Sección Básica / Basic

Artículo de investigación / Research paper

\title{
Las hormigas Pheidole (Formicidae: Myrmicinae) en el bosque seco tropical de Santa Marta, Colombia
}

\author{
The Pheidole ants (Formicidae: Myrmicinae) in the tropical dry forest of \\ Santa Marta, Colombia
}

\author{
JOSÉ J. CAMARGO-VANEGAS ${ }^{1}$; ROBERTO J. GUERRERO²
}

\begin{abstract}
${ }^{1}$ Biólogo. Grupo de Investigación en Insectos Neotropicales. Universidad del Magdalena, Carrera $32 \mathrm{~N}^{\circ}$ 22-08, San Pedro Alejandrino, Santa Marta, Colombia, jocam0403@gmail.com, https://orcid.org/0000-0001-9645-4485. 22 Doctor en Zoología. Grupo Insectos Neotropicales, Programa de Biología, Facultad de Ciencias Básicas, Universidad del Magdalena, Carrera 32 \# 22-08, Santa Marta, Magdalena, Colombia, rguerrero@unimagdalena.edu.co, https://orcid. org/0000-0003-3244-2754
\end{abstract}

\begin{abstract}
Autor para correspondencia
Roberto J. Guerrero. Doctor en Zoología. Grupo Insectos Neotropicales, Programa de Biología, Facultad de Ciencias Básicas, Universidad del Magdalena. Carrera 32 \# 22-08, Santa Marta, Magdalena, Colombia,rguerrero@unimagdalena.edu.co, https://orcid.org/0000-0003-32442754.

\section{Citación sugerida}

CAMARGO-VANEGAS, J. J.; GUERRERO, R. J. 2020. Las hormigas Pheidole (Formicidae: Myrmicinae) en el bosque seco tropical de Santa Marta, Colombia. Revista Colombiana de Entomología 46 (2): e8433. https://doi.org/10.25100/ socolen.v46i2.8433
\end{abstract}

http://zoobank.org/urn:1sid:zoobank.org:pub: E5B54E74-EBD0-4C05-8F31-2E9FC99DAC10

Recibido: 20-ago-2019

Aceptado: 5-jun-2020

Publicado: 31-dic-2020

Revista Colombiana de Entomología ISSN (Print): 0120-0488

ISSN (On Line): 2665-4385

https://revistacolombianaentomologia.univalle.edu.co

Open access

(c) (i) (2) (2) BY-NC-SA 4.0

CYY NC SA creativecommons.org/licenses/by-nc-sa/4.0/deed.es

Publishers: Sociedad Colombiana de Entomología SOCOLEN (Bogotá, D. C., Colombia) https://www.socolen.org.co

Universidad del Valle (Cali, Colombia)

https://www.univalle.edu.co

(C) 2020 Sociedad Colombiana de Entomología - SOCOLEN y Universidad del Valle - Univalle
Resumen: Las hormigas son un componente biótico conspicuo dentro del bosque seco tropical, debido a su gran diversidad tanto a nivel de especies como funcional. Del conjunto de hormigas se destacan las del género Pheidole (Formicidae: Myrmicinae), categorizadas como grupo hiperdiverso por el alto número de especies que presenta en cualquier tipo de bosque tropical. Esta característica hace de este grupo un reto taxonómico durante el desarrollo de estudios de diversidad y ecología, por lo tanto, estudios locales que ofrezcan información sobre la identidad de las especies de Pheidole de un área determinada, se convierten en un recurso importante para la toma de decisiones. En este trabajo se documentó la fauna de hormigas del género Pheidole en diferentes formaciones de bosque seco tropical en Santa Marta, Colombia. Se registran 13 especies de las cuales Pheidole guajirana amplía su distribución al departamento del Magdalena, mientras que $P$. impressa y $P$. leptina son registradas por primera vez en el país. También se ofrece la diagnosis y descripción de la nueva especie $P$. urbana y sus rasgos morfológicos son comparados con especies similares del grupo informal "flavens". Se evalúa y discute la riqueza de especies del género en los diferentes sitios de muestreo. Se ofrecen características morfológicas distintivas para cada una de las especies. Además, se discute la variabilidad morfológica y se incluyen fotografías a color para las soldados (= obrera mayor) y obreras (= obrera menor) de cada una de las especies registradas.

Palabras clave: Biodiversidad, ecosistemas boscosos amenazados, nuevos registros, Sierra Nevada de Santa Marta, taxonomía, Hymenoptera, Formicidae, Pheidole.

Abstract: Ants are a conspicuous biotic component within the tropical dry forest, due to their great diversity both at the species and functional level. Of all the ants, those of the genus Pheidole (Formicidae: Myrmicinae) stand out, which have been categorized as a hyperdiverse group due to the high number of species. The latter has made this group a taxonomic challenge during the development of diversity and ecology studies, therefore, local studies that offer information on the identity of the Pheidole species of a given area becomes an important resource for the decision making. The ants of the genus Pheidole in different formations of tropical dry forest in Santa Marta were studied. Thirteen species are registered, of which Pheidole guajirana extends its distributional range to the department of Magdalena, while $P$. impressa and $P$. leptina are registered for the first time in the country. The diagnosis and description of the new species $P$. urbana is also offered and its morphological features are compared with similar species of the "flavens" informal group. The species richness of the genus in the different sampling sites is evaluated and discussed. Distinctive morphological characteristics are offered for each of the species. Moreover, morphological variability is discussed, and multifocal color images are included for the soldiers (major worker) and workers (= minor worker) of each of the registered species.

Keywords: Biodiversity, threatened forest ecosystems, new records, Sierra Nevada de Santa Marta, taxonomy, Hymenoptera, Formicidae, Pheidole.

\section{Introducción}

Las hormigas del género Pheidole Westwood, 1839 (Formicidae: Myrmicinae) son uno de los grupos más diversos dentro de esta familia de insectos, con más de 1.100 especies descritas (Moreau 2008; Fischer et al. 2012; Bolton 2020), las cuales poseen su epicentro de diversidad en el Nuevo Mundo con más de 750 especies (Wilson 2003; Longino 2019), conformando aproximadamente el $10 \%$ de la fauna total de hormigas descritas a nivel mundial (Economo et al. 2015); esto junto a su amplia 
distribución, no sólo hacen de este género un ejemplo de éxito en términos de ecología y diversidad de especies (Fischer et al., 2012), sino un modelo para estudios evolutivos (Economo et al. 2015), biogeográficos (Sarnat y Moraeu 2011), neurobiología (Giraldo et al. 2013) y exploración de nuevas herramientas en estudios anatómicos (Lillico-Ouachour et al. 2018).

Las hormigas Pheidole se destacan por presentar un fuerte dimorfismo en la casta infértil (soldado y obrera sensu Peeters (2019)), diferencias morfológicas que permiten el desarrollo de diferentes tareas dentro de la colonia, como forrajeo y defensa, cuidado de las crías o procesamiento del alimento (Mertl et al. 2010). Morfológicamente, la gran mayoría de especies presentan 12 flagelómeros con los últimos tres formando una clava, pero hay variaciones desde 10 a 12 flagelómeros, presentan una depresión promesonotal variable en forma y profundidad $\mathrm{y}$, generalmente, una cara posterior en el mesonoto (Fernández 2003), surco metanotal bien marcado, propodeo con espinas, dientes o dentículos, pero muy raras veces desarmado, peciolo pedunculado, nodo peciolar sin algún tipo de espinas o protuberancias (Wilson 2003; Fernández y Serna 2019).

Colombia, con cerca de 1.200 especies de hormigas (Guerrero et al. 2018), constituye una de las zonas con mayor riqueza de hormigas en el Neotrópico; sin embargo, los registros para taxones hiperdiversos como Pheidole en este país son relativamente escasos (Zabala et al. 2006; Fernández 2003, 2011; Achury et al. 2012; Chacón de Ulloa et al. 2012); la compleja morfología de las especies, la dificultad metodológica de algunos recursos taxonómicos y la ausencia de colecciones de referencias, imposibilitan la identificación de las especies a escala regional y nacional. En consecuencia, la diversidad del género Pheidole en el país parece estar subestimada; no obstante, iniciativas dirigidas a conocer la composición, riqueza y distribución de este género (proyecto Pheidole de Colombia) han mejorado el estado del conocimiento de este grupo de hormigas en el país (Guerrero et al. 2018).

Así mismo, se conoce poca información sobre la biología, ecología y distribución de las especies Pheidole para el territorio nacional, especialmente en aquellos ecosistemas sujetos a potenciales grados de perturbación como ecosistemas boscosos de alta montaña o los remanentes de bosque seco en el país; no obstante, algunos estudios en bosque seco para el valle geográfico del río Cauca incluyen a las hormigas Pheidole dentro de sus análisis (Achury et al. 2012; Chacón de Ulloa et al. 2012). Para contribuir al conocimiento de la diversidad de hormigas del país, sobre todo de aquellos ambientes que han recibido poca atención, se documentó la fauna de hormigas del género Pheidole (Formicidae: Myrmicinae) en diferentes formaciones de bosque seco tropical en Santa Marta (Magdalena); para esto se definió la identidad taxonómica de cada una de las especies, incluyendo la descripción de una nueva especie, analizó la variabilidad morfológica intraespecífica y analizó la riqueza del género para las diferentes áreas estudiadas. Esta información no sólo permite reconocer taxonómicamente las especies que allí habitan, sino que establece cimientos para el desarrollo de estudios ecológicos y de biología de la conservación en el bosque seco tropical.

\section{Materiales y métodos}

Fase de campo. El estudio se realizó en cuatro áreas de bosque seco tropical ubicadas en diferentes zonas de Santa Marta (Fig. 1). En cada área se estableció una estación de muestreo (Tabla 1), donde dos personas realizaron captura manual directamente de los nidos por un periodo de cuatro horas.

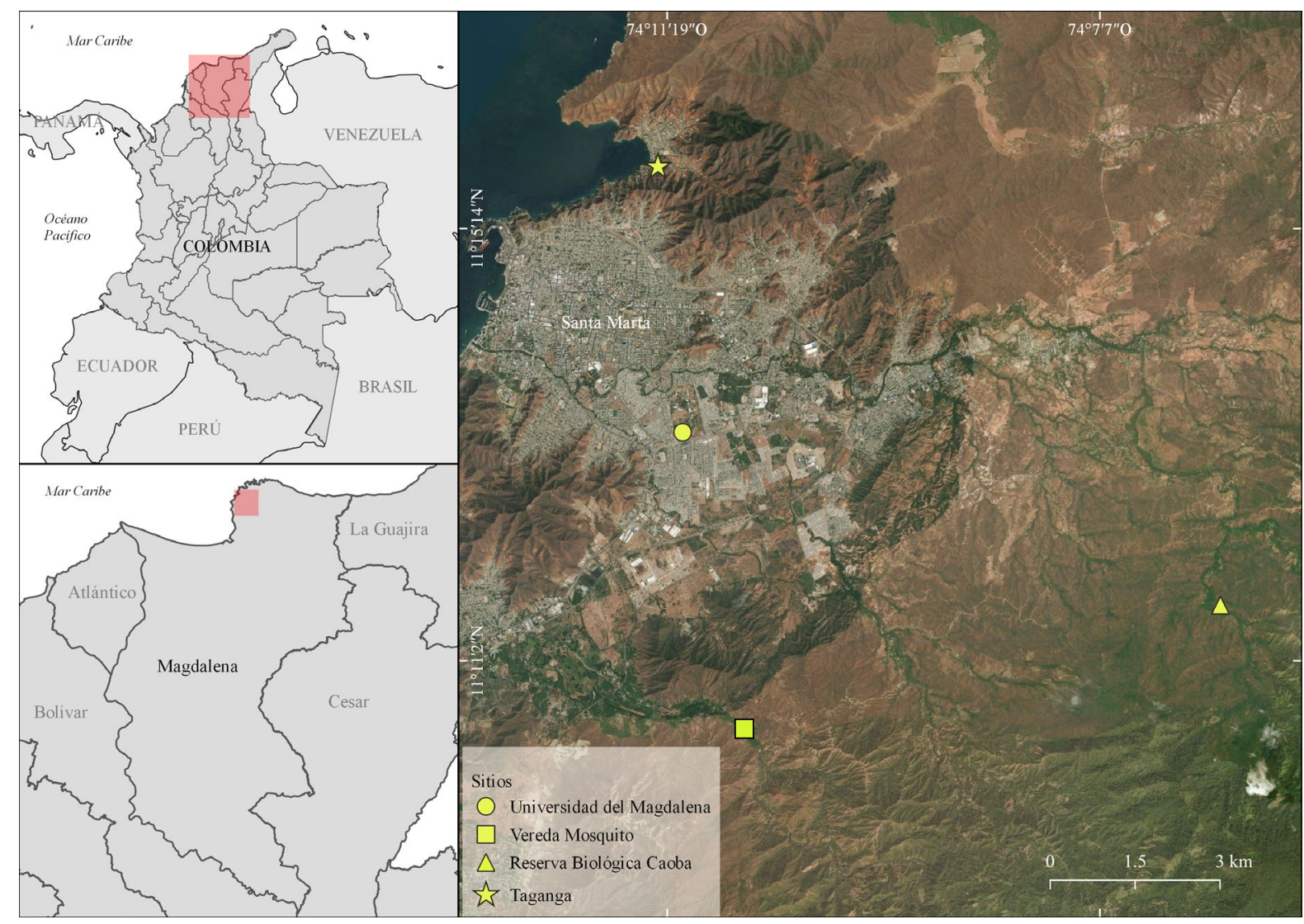

Figura 1. Mapa del área de estudio, donde se indican las cuatro estaciones de muestreo en Santa Marta. 
Tabla 1. Información asociada a cada una de las estaciones de muestreo de hormigas Pheidole en el bosque seco tropical de Santa Marta (Magdalena, Colombia).

\begin{tabular}{|c|c|c|c|}
\hline Nombre de la estación & Fecha de muestreo & Ubicación geográfica & Características del sitio \\
\hline $\begin{array}{l}\text { Parcela bosque seco } \\
\text { Universidad del Magdalena }\end{array}$ & $\begin{array}{l}18 \text { agosto } 2018 \text { y } 12,13 \\
\text { septiembre } 2018\end{array}$ & $\begin{array}{l}11^{\circ} 13^{\prime} 18,08^{\prime \prime} \mathrm{N}, \\
74^{\circ} 11^{\prime} 11,25^{\prime \prime} \mathrm{O}, 30 \mathrm{~m}\end{array}$ & $\begin{array}{l}\text { Formación de bosque seco tropical con } \\
\text { dos periodos de lluvia anual (Strewe et } \\
\text { al. } 2009 \text { ). Precipitación anual promedio } \\
\text { de } 578 \mathrm{~mm} \text {; temperatura promedio anual } \\
\text { de } 27^{\circ} \mathrm{C} \text { (Noriega et al. 2016). }\end{array}$ \\
\hline Puerto Mosquito & $\begin{array}{l}23,26 \text { junio } 2018 \text { y } 23 \text { agosto } \\
2018\end{array}$ & $\begin{array}{l}11^{\circ} 10^{\prime} 26^{\prime \prime} \mathrm{N}, 74^{\circ} 10^{\prime} 37^{\prime \prime} \mathrm{O}, \\
50 \mathrm{~m}\end{array}$ & $\begin{array}{l}\text { Formación de bosque seco y muy seco } \\
\text { tropical, donde las lluvias precipitan du- } \\
\text { rante dos o tres meses al año (Tamaris- } \\
\text { Turizo et al. 2013) }\end{array}$ \\
\hline Reserva Biológica Caoba & $\begin{array}{l}27 \text { octubre } 2018 \text { y } 12,13 \\
\text { noviembre } 2018\end{array}$ & $\begin{array}{l}11^{\circ} 11^{\prime} 35,59^{\prime \prime} \mathrm{N}, \\
74^{\circ} 5,58,02^{\prime \prime} \mathrm{O}, 337 \mathrm{~m}\end{array}$ & $\begin{array}{l}\text { Área en recuperación, con formaciones } \\
\text { de bosque seco tropical, parches de bos- } \\
\text { que de galería y algunos componentes } \\
\text { de bosque húmedo tropical. }\end{array}$ \\
\hline Taganga & $\begin{array}{l}23,27 \text { septiembre } 2018 \text { y } 10 \\
\text { octubre } 2018\end{array}$ & $\begin{array}{l}11^{\circ} 16^{\prime} 09,15^{\prime \prime} \mathrm{N}, \\
74^{\circ} 11^{\prime} 46,35^{\prime} \mathrm{O}, 1,5 \mathrm{~m}\end{array}$ & $\begin{array}{l}\text { Formación de bosque muy seco y subxe- } \\
\text { rofítico. Temperatura promedio anual de } \\
28{ }^{\circ} \mathrm{C} \text {; precipitación promedio anual de } \\
578 \mathrm{~mm} \text { (Iglesias Córdoba et al. 2008). }\end{array}$ \\
\hline
\end{tabular}

Para un óptimo desempeño de la captura manual, en toda el área de la estación se distribuyeron diez cebos compuestos de galleta de frutos secos ricas en aceites. Los cebos fueron revisados constantemente para visualizar hormigas cargando material hacia sus nidos. Las obreras cargadas de cebo fueron seguidas y una vez identificada la entrada del nido, este fue excavado cuidadosamente para recolectar principalmente las soldados y obreras, las cuales son claves para la identificación taxonómica de las especies; también se recolectaron huevos y larvas que no fueron tenidas en cuenta en este estudio. Cada estación de muestreo se visitó tres veces durante el transcurso del estudio. El material recolectado se rotuló con la información del sitio de muestreo y se preservó en etanol al $96 \%$.

Fase de laboratorio. Las muestras fueron separadas de acuerdo a similitudes morfológicas (morfotipos), teniendo en cuenta las soldados y las obreras recolectados en los nidos; algunas obreras aisladas fueron comparadas e identificadas posteriormente con esas provenientes de los nidos. De cada morfotipo se seleccionaron varios ejemplares que fueron preparados de acuerdo a Guerrero et al. (2019). La identificación taxonómica se hizo usando las claves LucidKey v3.3 provistas por el "Pheidole working group" (Longino 2009a), las descripciones morfológicas de Wilson (2003) y la biblioteca de imágenes de Antweb (2019). La diagnosis y descripción de Pheidole urbana n. sp. se hizo teniendo en cuenta el esquema de trabajo de Longino (2009b; 2019). Previamente, los ejemplares soldados y obreras de este "morfotipo" fueron comparados con las especies del recurso digital "Pheidole working group LucidKey" a cargo del Dr. John T. Longino (Universidad de Utah) que contiene a todas las especies descritas por Wilson (2003) y los cambios taxonómicos hechos posteriormente por Longino (2009b) y Longino (2019); el uso del recurso digital LucidKey permitió estrechar el conjunto de especies de Pheidole formalmente descritas para todo el continente americano, dejando así un subconjunto de tres especies vecinas que comparten un espacio morfométrico con P. urbana n. sp. Posteriormente, las soldados y obreras de P. urbana n. sp. fueron contrastadas con las descripciones de esas especies provistas por Wilson (2003) y fotografías de alta resolución depositadas en bibliotecas virtuales (para ampliar, ver Diagnosis de $P$. urbana n. sp.). Para identificar a $P$. indica Mayr, 1879, una especie introducida a nivel mundial, se utilizó la clave taxonómica de Eguchi (2008). Todo el material fue depositado en el Centro de Colecciones Biológicas de la Universidad del Magdalena (CBUMAG: Registro Nacional de Colecciones Biológicas N²07).

Análisis morfométrico. Las características morfométricas consistieron de medidas que son muy útiles en la sistemática de las especies del género Pheidole (Longino 2009b; Longino 2019). Las medidas fueron tomadas en aumento de $60 \mathrm{X}$ usando un estereoscopio Stemi 305 equipado con una regla milimétrica de precisión 0,01. Todas las medidas son dadas en milímetros y corresponden a las siguientes: Longitud de la cabeza (LC), en vista frontal de la cabeza, longitud máxima de la cabeza desde la línea tangente a la proyección más anterior de la cabeza hasta la línea tangente a la proyección más posterior del margen del vértice posterior cefálico; Ancho de la cabeza (AC), en vista frontal, el ancho máximo de la cápsula cefálica excluyendo los ojos; Longitud del escapo (LE), longitud del eje del escapo desde la base hasta el ápice, sin incluir el cóndilo basal y el cuello. Longitud mesosoma (LM): en vista lateral, la distancia desde la base de la cara anterior del pronoto, en el punto de inflexión entre la cara anterior con pendiente descendente, y la proyección anterior con forma de reborde hasta la extensión más posterior de la metapleura. Además, se calcularon una serie de índices donde se relacionan algunas medidas: Índice cefálico $(\mathrm{IC})=(\mathrm{AC} / \mathrm{LC}) * 100$. Índice del escapo $(\mathrm{IE})=(\mathrm{LE} / \mathrm{AC}) * 100$.

La variabilidad morfológica de las especies se evaluó comparando caracteres morfológicos como pilosidad, coloración y superficie corporal, entre las diferentes poblaciones o en algunos casos, con imágenes de alta resolución descargadas del portal AntWeb (2019). Para la definición de tipo de pilosidad y terminología de la morfología se siguió a Delsinne et al. (2019), mientras que las descripciones de la escultura de la superficie se hicieron con base en Harris (1979).

Mapa. El mapa de la zona de estudio se generó utilizando el programa QGIS 2.16 (Team QGIS Development 2016). Para la ubicación de las coordenadas de los sitios de muestreo se utilizó una capa de imagen satelital de Google descargada 
a través de Quick Maps Service y Natural Earth 2.0 (Natural Earth 2019). Las coordenadas geográficas fueron registradas con un GPS Garmin GPSMAP® 62st usando el sistema WGS84.

Imágenes. La forma de la soldado y la obrera se muestra a partir de imágenes multifoco generadas utilizando un estereoscopio automatizado Leica M250A equipado con una cámara Leica DFC540. El ensamblaje automático de las diferentes fotografías fue procesado con el módulo LAS de Leica ${ }^{\circledR}$. Los ajustes de brillo y contraste fueron realizados con la opción Editar imagen del módulo LAS de Leica ${ }^{\circledR}$.

\section{Resultados}

Riqueza de especies y composición. Se recolectaron y estudiaron un total de 112 individuos distribuidos en 13 especies. Puerto Mosquito y la Reserva Biológica Caoba fueron los sitios con mayor número de especies, con 6 y 7 respectivamente, mientras que la Universidad del Magdalena (UniMagdalena) y Taganga registraron tres especies cada una. La Reserva Biológica Caoba compartió cuatro especies con el ensamblaje de hormigas Pheidole que habitan en Puerto Mosquito, mientras que la parcela de bosque seco de la UniMagdalena solo compartió dos especies con Puerto Mosquito. A pesar de la complementariedad relativamente alta entre los sitios (medido como número de especies compartidas), las especies de Pheidole en Taganga son exclusivas de ese sitio (Tabla 2). De las especies compartidas entre al menos dos sitios, se destaca $P$. fallax Mayr, 1870 como una de las especies más frecuentes, definida así según los registros de frecuencia de captura en la mayoría de las estaciones estudiadas (Tabla 2); esta especie presentó una alta densidad de nidos (más de 15 nidos/ hectárea) en sitios como el bosque seco de la UniMagdalena (Ramírez y Guerrero, datos sin publicar).

Por otro lado, Pheidole impressa Mayr, 1870 y P. leptina Wilson, 2003 son registradas por primera vez para el país, mientras que $P$. guajirana Wilson, 2003 amplía su distribución al departamento del Magdalena. Así mismo, se documenta por primera vez la presencia de $P$. indica Mayr, 1879 en área continental de Colombia.
Sinopsis taxonómica y caracterización de las especies. Pheidole fallax Mayr, 1870. Bahamas, Puerto Rico, Antillas Menores, Cuba, México, Guatemala, Honduras, Nicaragua, Costa Rica, Panamá, Perú, Bolivia, Brasil, Paraguay, Uruguay, Argentina, Venezuela, Guyana, Surinam, Guayana Francesa. En Colombia se conoce en el Atlántico, Magdalena y La Guajira. Distribución registrada en Serna et al. (2019).

Pheidole guajirana Wilson, 2003. Venezuela. En Colombia se conoce en La Guajira (Serna et al. 2019) y Magdalena. Pheidole impressa Mayr, 1870. Guayana Francesa, Brasil. En Colombia, solo conocida en el Magdalena.

Pheidole indica Mayr, 1879. Especie vagabunda (trap species), registrada para Colombia en San Andrés islas (Guerrero et al. 2018) y Magdalena.

Pheidole inversa Forel, 1901. Ecuador. En Colombia se conoce en Magdalena y Atlántico. Distribución registrada en Serna et al. (2019).

Pheidole leptina Wilson, 2003. Brasil, Colombia y Perú. En Colombia, solo conocida en el Magdalena.

Pheidole pugnax Dalla Torre, 1892. El Salvador, Honduras, Nicaragua, Costa Rica, Panamá, Colombia, Guayana Francesa. En Colombia se conoce en Caquetá (Mpio. La Esperanza) y Magdalena.

Pheidole radoszkowskii Mayr, 1884. Jamaica, Antillas Menores, Trinidad y Tobago, México, Guatemala, Honduras, El Salvador, Nicaragua, Costa Rica, Panamá, Perú, Bolivia, Brasil, Venezuela, Guyana, Surinam, Guayana Francesa Uruguay, Paraguay, Argentina. En Colombia se conoce en Magdalena, Atlántico, Risaralda y Valle del Cauca. Distribución registrada en Serna et al. (2019).

Pheidole reclusi Forel, 1899. En Colombia se conoce en Magdalena, Cundinamarca y Valle del Cauca.

Pheidole steinheili Forel, 1901. En Colombia se conoce en La Guajira, Magdalena y Atlántico.

Pheidole subarmata Mayr, 1884. Bahamas, Cuba, República Dominicana, Haití, Puerto Rico, Antillas Menores, Trinidad y Tobago, México, Guatemala, Honduras, El Salvador, Nicaragua, Costa Rica, Panamá, Ecuador, Paraguay, Uruguay, Argentina, Brasil, Venezuela, Guyana, Surinam, Guayana Francesa. En Colombia se conoce en Magdalena y Risaralda. Distribución registrada en Serna et al. (2019).

Tabla 2. Listado de las hormigas del género Pheidole que habitan en cuatro estaciones de bosque seco tropical en la región de Santa Marta, incluyendo la frecuencia de observaciones/captura para cada estación de muestreo. (X: recolectada sólo en una visita a la estación de muestreo; XX: recolectada en dos visitas a la estación de muestreo; XXX: recolectada en las tres visitas a la estación de muestreo).

\begin{tabular}{|c|c|c|c|c|}
\hline \multirow{2}{*}{ Especie } & \multicolumn{4}{|c|}{ Localidad } \\
\hline & $\begin{array}{c}\text { Reserva Biológica } \\
\text { Caoba }\end{array}$ & Puerto Mosquito & Taganga & $\begin{array}{c}\text { Universidad del } \\
\text { Magdalena }\end{array}$ \\
\hline Pheidole fallax Mayr, 1870 & XXX & XXX & & XXX \\
\hline Pheidole guajirana Wilson, 2003 & & $\mathrm{X}$ & & $\mathrm{X}$ \\
\hline Pheidole impressa Mayr, 1870 & $\mathrm{XXX}$ & $\mathrm{X}$ & & \\
\hline Pheidole indica Mayr, 1879 & & & $\mathrm{XX}$ & \\
\hline Pheidole inversa Forel, 1901 & & & XXX & \\
\hline Pheidole leptina Wilson, 2003 & $\mathrm{X}$ & $\mathrm{X}$ & & \\
\hline Pheidole pugnax Dalla Torre, 1892 & $\mathrm{XX}$ & & & \\
\hline Pheidole radoszkowskii Mayr, 1884 & & $\mathrm{X}$ & & \\
\hline Pheidole reclusi Forel, 1899 & $\mathrm{X}$ & & & \\
\hline Pheidole steinheili Forel, 1901 & & $\mathrm{XX}$ & & \\
\hline Pheidole subarmata Mayr, 1884 & XXX & $\mathrm{XX}$ & & \\
\hline Pheidole transversostriata Mayr, 1887 & & & & $\mathrm{X}$ \\
\hline Pheidole urbana $\mathrm{n} . \mathrm{sp}$. & & & $\mathrm{XX}$ & \\
\hline
\end{tabular}


Pheidole transversostriata Mayr, 1887. Puerto Rico, Antillas Menores, Trinidad y Tobago, Guyana, Surinam, Guayana Francesa, Brasil, Venezuela. En Colombia se conoce en Magdalena, Cesar, Risaralda y Valle del Cauca. Distribución registrada en Serna et al. (2019).

Pheidole urbana $\mathrm{n}$. sp. Colombia. Conocida solamente de Santa Marta (Magdalena, Colombia).

\section{Pheidole fallax Mayr, 1870}

(Fig. 2)

Soldado. Medidas ( $\mathrm{n}=5$ ): LC 1,81-1,90; AC 1,73-1,79; LE 0,81-0,94; LM 1,40-1,52; IC 50-53; IE 93-97. Las soldados de $P$. fallax pueden ser reconocidas por presentar en vista dorsal, cóstulas longitudinales que van desde el lóbulo frontal hasta el margen posterior de la cabeza, y márgenes laterales de la cabeza rugoreticulados. En vista lateral, margen occipital relativamente estrecho con la mitad posterior de la cabeza carinulada. Pronoto transversalmente carinulado en vista dorsal. En vista lateral, para ambas castas (soldado y obrera), nodo peciolar prominente, que desciende hasta el pedúnculo mediante una fuerte concavidad en sentido posteroanterior y cae casi verticalmente hasta la inserción pospeciolar en sentido anteroposterior.

Área entre el ojo y la fosa antenal con rugoretículos que además cubren los márgenes laterales de la cabeza; margen hipostomal plano, ausencia de dientes hipostomales internos; escasa pilosidad erecta en el margen posterior y márgenes la- terales de la cabeza. En vista lateral, la cabeza se estrecha hacia el margen occipital, con la mitad posterior de la cabeza principalmente carinulada. Pronoto en vista dorsal, carinulado transversalmente; en vista lateral, mesonoto y propodeo foveado-reticulado, presencia de surco promesonotal y espinas propodeales, pilosidad erecta y dispersa en todo el mesosoma al igual que en la coxa. En vista lateral, peciolo y pospeciolo densamente foveados. En vista dorsal, primer segmento del gáster áspero, resto del gaster liso y brillante; hormiga marrón oscuro a marrón rojizo, con el gaster bicolor. En vista lateral, abundante pilosidad erecta en el gáster.

Obrera. Medidas ( $\mathrm{n}=5)$ : LC 1,70-1,77; AC 1,64-1,75; LE 0,85-0,98; LM 0,84-0,96; IC 82-98; IE 128-138. Cabeza, en vista dorsal, lisa y brillante, escapos antenales largos que sobrepasan por mucho el borde posterior de la cabeza LE 0,85-0,98; margen occipital estrecho con cuello nucal muy delgado, apenas perceptible; pilosidad erecta y dispersa. En vista dorsal, pronoto provisto de carenas transversas débiles. En vista lateral, pronoto liso y brillante, resto del mesosoma densamente foveado, mesosoma con muy pocas setas erectas, coxa, fémur y tarsos opacos, con pilosidad dispersa y erecta. En vista lateral, región dorsal del peciolo y pospeciolo liso y brillante, región ventral foveado, nodo peciolar prominente que desciende hasta el pedúnculo mediante una fuerte concavidad y cae casi verticalmente hasta la inserción pospeciolar. En vista lateral, gaster liso y brillante, con pelos erectos dispersos. Color marrón claro.
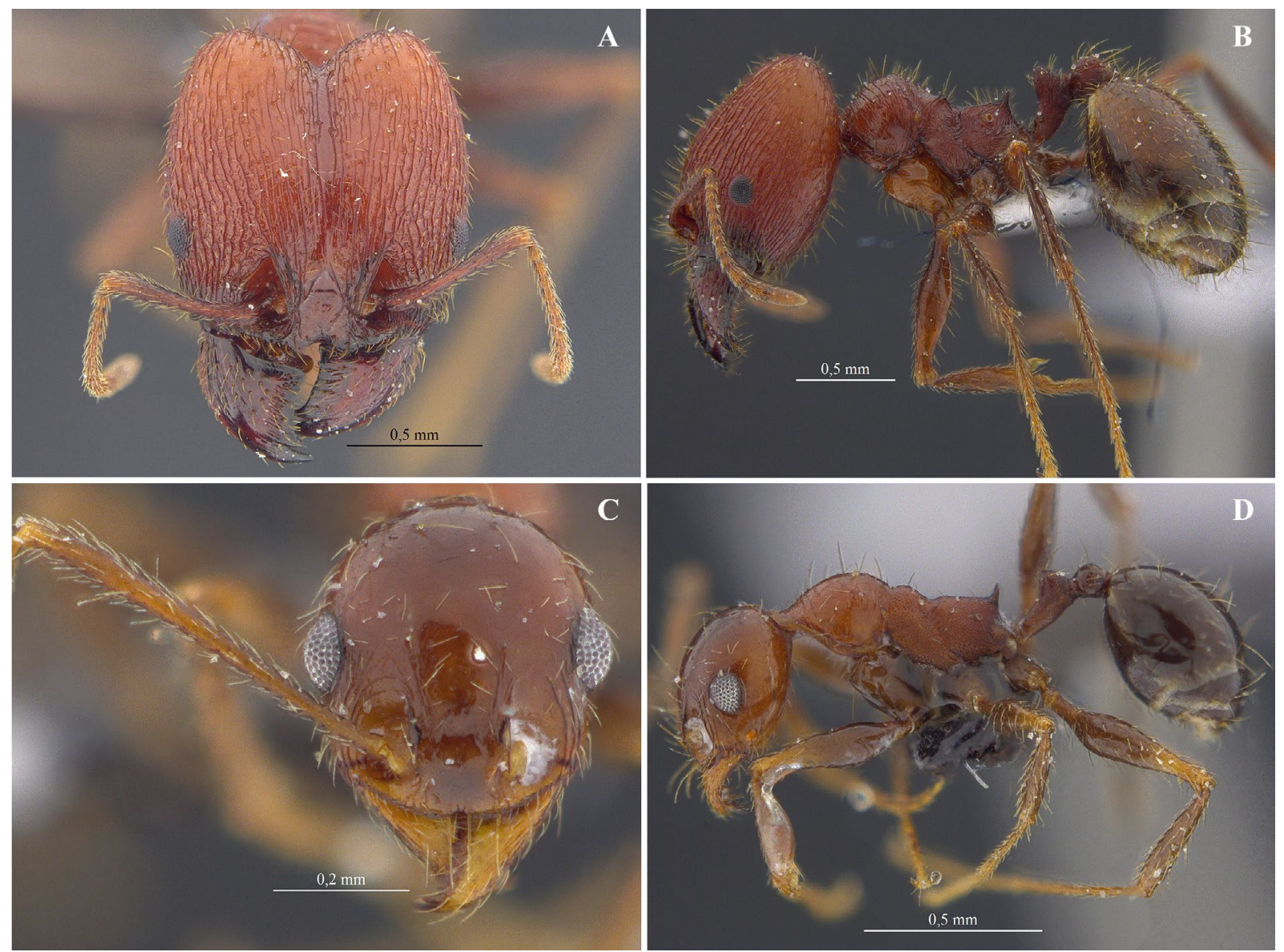

Figura 2. Hábito de la obrera de Pheidole fallax Mayr, 1870. A. Cabeza en vista frontal de la soldado. B. Cuerpo en vista lateral de la soldado. C. Cabeza en vista frontal de la obrera. D. Cuerpo en vista lateral de la obrera. Fotografías de soldado (CBUMAG:ENT11088) y obrera (CBUMAG:ENT11095) por R. J. Guerrero. 
Variación morfológica. Las soldados pueden presentar variaciones de coloración desde marrón rojizo a marrón rojizo claro. Además, las poblaciones de Puerto Mosquito tienen soldados que presentan, en vista lateral, la mitad posterior de la cabeza carinulada con parches lisos y brillantes, mientras que aquellos de las poblaciones que habitan en la parcela de bosque seco en la UniMagdalena muestran una región lisa y brillante con carenas que sobrepasan levemente el ojo en sentido anteroposterior. Las carenas transversas en el pronoto pueden estar débilmente desarrolladas o muy desarrolladas cubriendo la mitad posterior del pronoto o la totalidad del mismo, esta variación se presenta intracolonial y entre las poblaciones de Puerto Mosquito, Caoba y la parcela de bosque seco de la UniMagdalena.

Biología. Pheidole fallax es muy común en el bosque seco tropical de Santa Marta; son hormigas generalistas que dominan los sitios en términos de frecuencia de captura (Tabla 2). Las colonias están presentes en áreas abiertas dentro o fuera del bosque y también en la vegetación ribereña en Caoba. Los nidos muchas veces se pueden identificar por montículos con restos de semillas o materiales de forrajeo alrededor de la entrada. Soldados y obreras forrajean en el área, llegando fácil y en gran número a los cebos. Las soldados expelen un olor fétido cuando son recolectadas.

Material examinado. 5 soldados, 7 obreras. COLOMBIA. Magdalena, Santa Marta, Puerto Mosquito, $11^{\circ} 10^{\prime} 37,06^{\prime \prime} \mathrm{N}$ $74^{\circ} 11^{\prime} 6,611^{\prime \prime O}, 50 \mathrm{~m}$, captura manual, 23-jun-2018. Camargo, J. [CBUMAG]. 25 soldados, 18 obreras. Magdalena, bosque seco de la UniMagdalena, $11^{\circ} 13^{\prime} 17,58^{\prime}{ }^{\circ} \mathrm{N} 74^{\circ} 11^{\prime} 10,86^{\prime} \mathrm{O}, 30$ $\mathrm{m}$, captura manual, 12-sep- 2018. Camargo, J. [CBUMAG]. 7 soldados, 5 obreras. Magdalena, Santa Marta, Reserva Biológica Caoba, $11^{\circ} 11^{\prime} 31,56^{\prime} \mathrm{N}$ 745'59,99”O, 337 m, captura manual, 12-nov-2018. Camargo, J. [CBUMAG].

\section{Pheidole guajirana Wilson, 2003}

(Fig. 3)

Soldado. Medidas ( $\mathrm{n}=5)$ : LC 0,85-0,87; AC 0,63-0,75; LE 0,38-0,42; LM 0,63-0,67; IC 75-87; IE 45-49. Las soldados de $P$. guajirana pueden ser reconocidas por presentar en vista dorsal, cóstulas longitudinales que alcanzan dos tercios de la cabeza, lóbulos occipitales lisos y brillantes. En vista dorsal, para ambas castas (soldado y obrera) ojo bien adelante de la cabeza. Dorso promesonotal provisto de débiles carenas longitudinales. En vista lateral convexidad mesonotal bien desarrollada. En vista dorsal, pospeciolo en forma de diamante.

Cabeza con escrobos antenales débiles, margen hipostomal suavemente curvado, dientes hipostomales internos más próximos a la línea media respecto a los dientes hipostomales externos, presencia de un quinto diente hipostomal. Pilosidad erecta y dispersa en la cabeza. En vista lateral, cóstulas en la superficie de la gena apenas sobrepasan el ojo; mitad posterior de la cabeza lisa y brillante. En vista dorsal, pronoto foveado. En vista lateral, mitad anterior del pronoto lisa y brillante, mitad posterior foveado, mesonoto y propodeo foveoreticulados. En vista lateral, el mesosoma carece de surco promesonotal. Espinas propodeales reducidas a dentículos. Mesosoma con escasa pilosidad erecta. En vista lateral, peciolo y pospeciolo foveados. En vista lateral, gaster liso y brillante. Escasa pilosidad erecta en el gaster. Color marrón claro amarillento.
Obrera. Medidas ( $\mathrm{n}=5)$ : LC 0,40-0,42; AC 0,37-0,38; LE 0,33-0,37; LM 0,40-0,42; IC 86-95; IE 77-90. Cabeza, en vista dorsal, densamente foveada, margen occipital ancho sin presencia de cuello nucal. Triangulo frontal y lóbulo del vértex costulados. En vista frontal, los escapos alcanzan el borde posterior LE 0,33-0,37. Cabeza provista de pocas setas erectas. En vista lateral, las fóveas sobrepasan levemente el ojo en sentido anterior-posterior. Mitad posterior de la cabeza lisa y brillante en vista lateral. Mesosoma, peciolo y pospeciolo densamente foveados en vista dorsolateral. Pilosidad dispersa y erecta en el mesosoma. En vista lateral, gaster liso y brillante. Color marrón claro, apéndices amarillos.

Variación morfológica. Los individuos de la localidad de Puerto Mosquito presentan en vista dorsal, pronoto relativamente liso, con carenas longitudinales poco marcadas, mientras que las poblaciones de la parcela en la UniMagdalena presentan carenas longitudinales en el pronoto, tal y como lo describe Wilson (2003). Las soldados presentan variaciones en el color, desde marrón claro a marrón oscuro y algunas negras, con apéndices amarillos recolectados en Puerto Mosquito.

Biología. Esta especie habita dentro de troncos húmedos o madera podrida en la vegetación cercana al río en la Reserva Caoba; la excavación de un nido permitió recolectar tanto obreras como machos; algunas obreras se observaron forrajeando sobre el suelo de la rivera, siendo atraídas por los cebos. La entrada del nido es excesivamente pequeña, muy parecida a los nidos de P. subarmata Mayr, 1884 y P. transversostriata Mayr, 1887.

Material examinado. 5 soldados, 7 obreras. COLOMBIA. Magdalena, Santa Marta, Puerto Mosquito, $11^{\circ} 10^{\prime} 37,06^{\prime \prime N}$ $74^{\circ} 11^{\prime} 6,611^{\prime \prime} \mathrm{O}, 50 \mathrm{~m}$, captura manual, 23-jun-2018. Camargo, J. [CBUMAG]. 2 soldados, 14 obreras. Magdalena. bosque seco de la UniMagdalena, $11^{\circ} 13^{\prime} 17,58^{\prime \prime} \mathrm{N} 74^{\circ} 11^{\prime} 10,86^{\prime} \mathrm{O}, 30$ m, captura manual, 18-abr-2012. Escárraga, M. [CBUMAG].

\section{Pheidole impressa Mayr, 1870} (Fig. 4)

Soldado. Medidas ( $\mathrm{n}=4)$ : LC 1,79-1,81; AC 1,67-1,73; LE 0,90-1,00; LM 1,44-1,54; IC 93-97; IE 50-56. Las soldados de $P$. impressa pueden ser reconocidas por presentar en vista dorsal, cabeza densamente rugoreticulada-punteada, en vista lateral mitad posterior de la cabeza principalmente carinulada. Pronoto provisto de carenas trasversales. En vista dorsal, nódulo pospeciolar en forma de trapecio y primer segmento del gáster notablemente estriado longitudinalmente.

Cabeza, en vista ventral, con dos pequeños dientes hipostomales internos y dos externos conspicuos. En vista dorsal, dorso promesonotal carinulado transversalmente. En vista lateral mesonoto y propodeo foveado-reticulados, presencia de surco promesonotal y espinas propodeales casi verticales a la cara propodeal basal. Presencia de pelos erectos y dispersos en el mesosoma. En vista lateral, peciolo y pospeciolo foveados. En vista lateral, gáster con superficie áspera con abundante pilosidad erecta. Color amarillo pardusco con apéndices negros.

Obrera. Medidas ( $\mathrm{n}=4)$ : LC 0,73-0,87; AC 0,60-0,67; LE 0,96-1,06; LM 0,81-1,19 IC 78-82; IE 122-132. Cabeza, en vista dorsal, con superficie áspera y provista de pequeños parches lisos y brillantes, escapos largos (IE 122-132) sobrepasando el margen posterior cefálico, margen occipital 

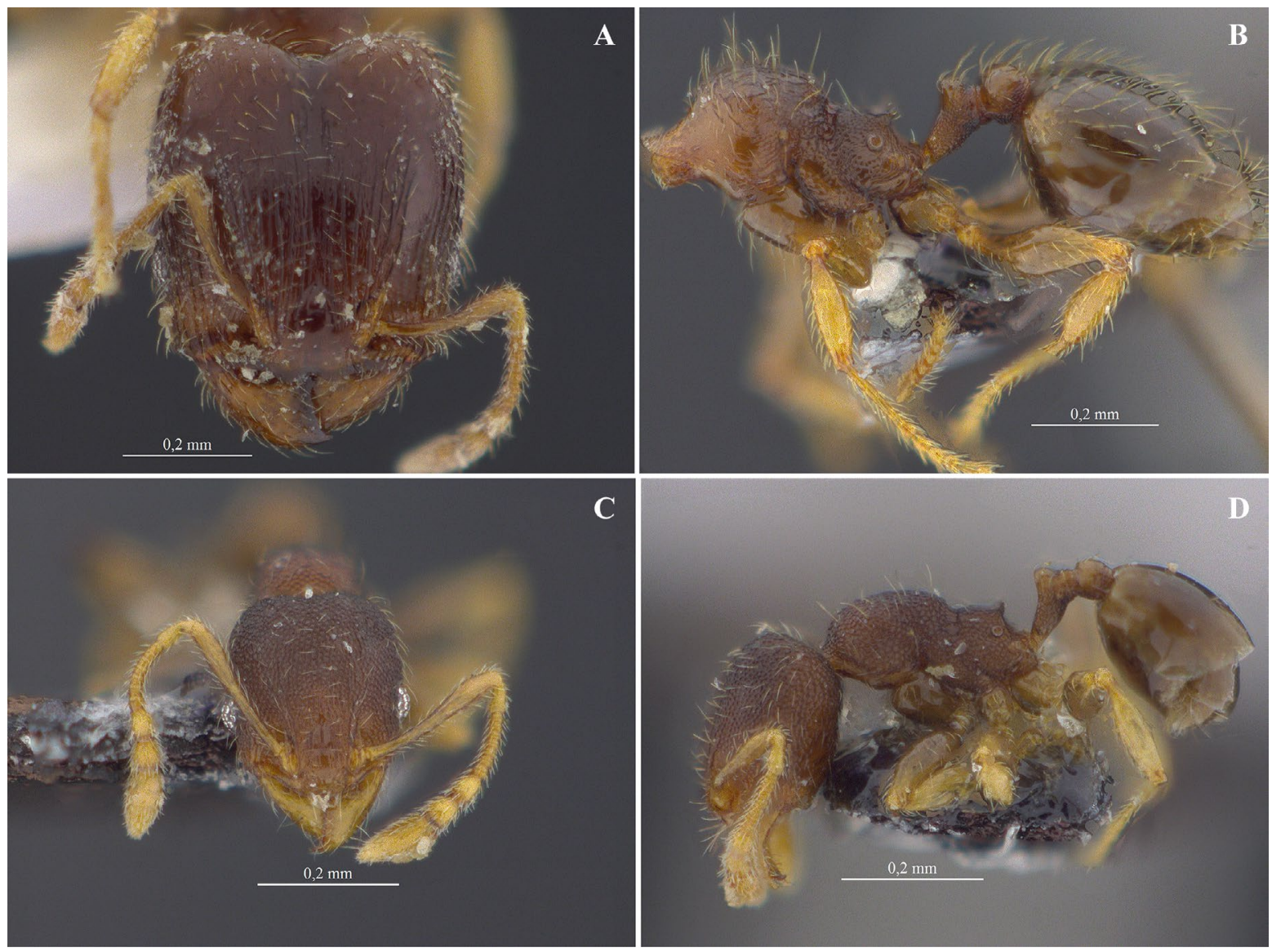

Figura 3. Hábito de la obrera de Pheidole guajirana Wilson, 2003. A. Cabeza en vista frontal de la soldado. B. Cuerpo en vista lateral de la soldado. C. Cabeza vista frontal de la obrera. D. Cuerpo en vista lateral de la obrera. La Figura 3B fue decapitada posterior a ser fotografiada la cabeza, de allí que el perfil del cuerpo de la hormiga aparezca sin este tagma. Fotografías de soldado (CBUMAG:ENT11143) y obrera (CBUMAG:ENT11154) por R. J. Guerrero.

estrecho, cuello nucal apenas perceptible. En vista lateral, pronoto fuertemente convexo, separado del mesonoto por una amplia depresión; en vista dorsal, pronoto con débiles carenas transversales, más perceptibles anteriormente. Mesonoto ligeramente convexo, formando una cara anterior corta y una posterior dos veces el largo de la primera; dorso de la cara anterior foveolado, mientras que la posterior con estrías transversas. Espinas propodeales pequeñas, tan cortas como el máximo diámetro del espiráculo propodeal. Patas con superficie lisa y brillante. En vista lateral, pronoto con superficie áspera, resto del mesosoma fuertemente foveolado. En vista lateral, peciolo y pospeciolo foveados. En vista lateral, superficie del gáster áspera pero brillante. Pelos largos, erectos y dispersos en todo el cuerpo. Cabeza incluyendo antenas, promesosoma y tarsos de las patas, marrón rojizo; propodeo, coxas, fémures, tibias, pecíolo y pospeciolo y marrón oscuro, gáster negro contrastando fuertemente con el resto del cuerpo.

Variación morfológica. Las soldados de Pheidole impressa presentan variaciones de color en la cabeza desde individuos amarillo pardusco (Puerto Mosquito) a individuos de marrón claro rojizo (Res. Biol. Caoba), aun cuando las poblaciones de ambas localidades presentaran cuerpos y apéndices de color negro. Las soldados de poblaciones de $P$. impressa provenientes de la localidad de Puerto Mosquito presentan dientes hipostomales internos bastante reducidos como lo ilustrado en Wilson (2003) y el diente hipostomal medio se encuentra vestigial, mientras que en las soldados de la Reserva Caoba los dientes hipostomales internos son casi imperceptibles y el del medio apenas proyectándose. Las soldados de $P$. impressa presentan variaciones en la escultura de la mitad posterior de la cabeza en vista lateral; algunos individuos de las poblaciones muestreadas de Puerto Mosquito y Caoba concuerdan con el parche liso y brillante que se describe en Wilson (2003) y presentan las fotografías del tipo (www.antweb.org: CASENT0919780), pero algunas soldados recolectadas en Puerto Mosquito (incluyendo esa de la Fig. 4), presentan esa región medio posterior del dorso de la cabeza rugoreticulada, pero la porción lateral y ventral de esa región es lisa como en la descripción. Esto sugiere que la especie $P$. impressa a lo largo de su actual distribución puede exhibir cierto grado de variación en la superficie de la región medio posterior del dorso de la cabeza.

Biología. Esta especie anida en el suelo descubierto, cerca al rio o dentro del bosque, siempre asociada a hábitats mayormente húmedos. También se han observado nidos entre rocas o montículos de tierra cerca al sendero del camino. Las obreras forrajean frecuentemente en el piso del bosque. Ambas castas son atraídas fácilmente a los cebos.

Material examinado. 1 soldado. COLOMBIA. Magdalena, Santa Marta, Puerto Mosquito, $11^{\circ} 10^{\prime} 37,06^{\prime \prime} \mathrm{N} 74^{\circ} 11^{\prime} 6,611^{\prime \prime O}$, $50 \mathrm{~m}$, captura manual, 26-jun-2018. Camargo, J. [CBUMAG]. 17 soldados, 11 obreras. Magdalena, Santa Marta, Reserva Biológica Caoba, $11^{\circ} 11^{\prime} 31,56^{\prime} \mathrm{N}^{7} 74^{\circ} 5^{\prime} 59,99^{\prime \prime O}, 50 \mathrm{~m}$, captura manual, 13-nov- 2018. Camargo, J. [CBUMAG]. 

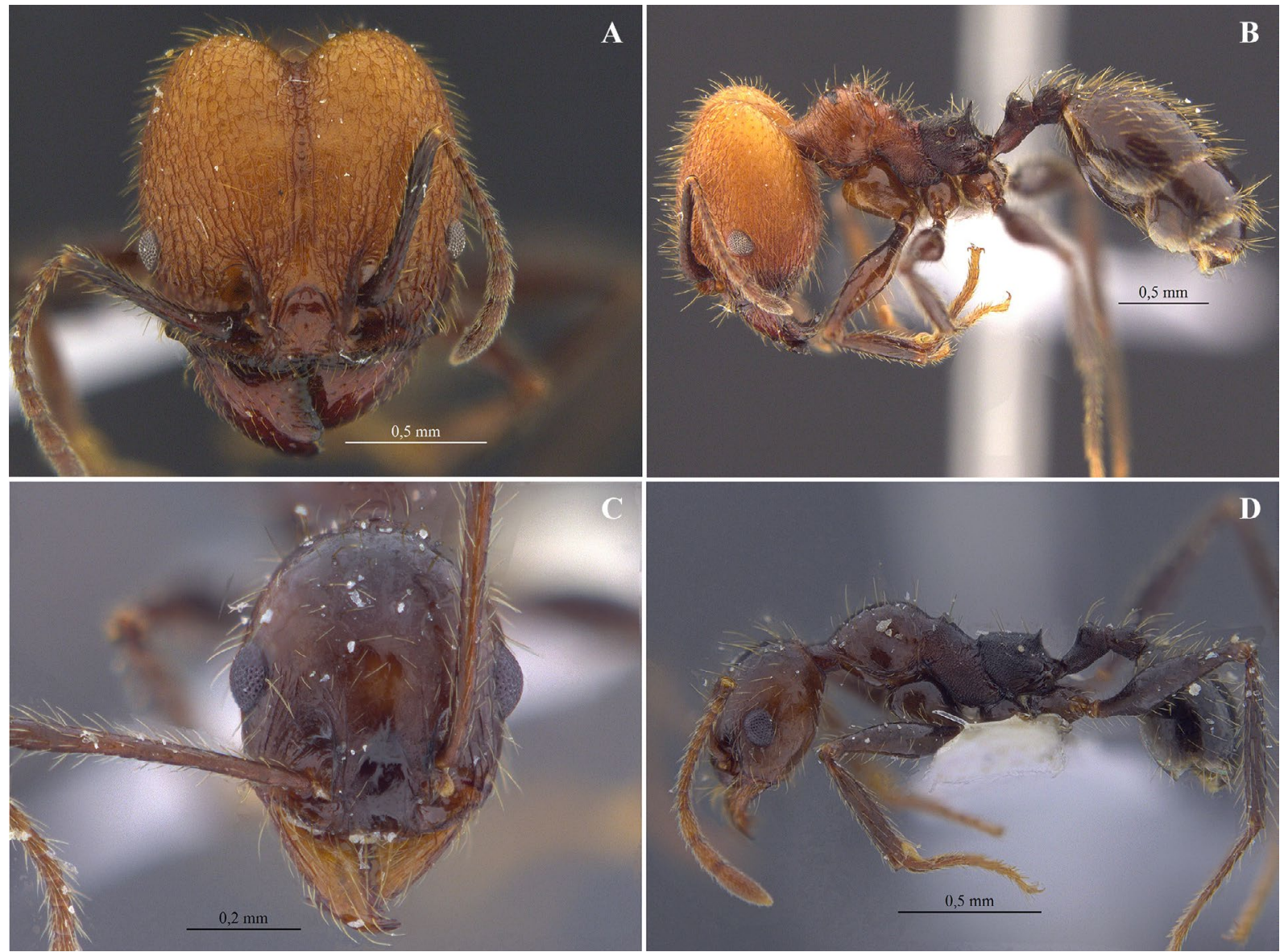

Figura 4. Hábito de Pheidole impressa Mayr, 1870. A. Cabeza en vista frontal de la soldado. B. Cuerpo en vista lateral de la soldado. C. Cabeza en vista frontal de la obrera. D. Cuerpo en vista lateral de la obrera. Fotografías de soldado (CBUMAG:ENT11160) y obrera (CBUMAG:ENT11161) por R. J. Guerrero.

\section{Pheidole indica Mayr, 1879}

(Fig. 5)

Soldado. Medidas ( $\mathrm{n}=5)$ : LC 1,33-1,52; AC 1,37-1,50; LE 0,81-0,85; LM 1,13-1,29; IC 99-104; IE 56-62. Las soldados de $P$. indica pueden ser reconocidas por presentar, en vista dorsal, cóstulas longitudinales que se extienden desde el lóbulo frontal hacia el vértice posterior cefálico, divergiendo hacia los lóbulos occipitales. Margen occipital fuertemente cóncavo. En vista lateral, fuerte convexidad en la región media de la mitad anterior de la cabeza. Márgenes laterales de la cabeza convexos, escrobas antenales bien desarrollados. Margen hipostomal plano, dientes hipostomales internos pequeños y agudos, dientes hipostomales externos más anchos en la base y longitud similar a los internos. En vista lateral mitad posterior de la cabeza mayormente carinulada hasta el margen occipital. En vista dorsal, pronoto carinulado transversalmente. En vista lateral pronoto liso y brillante provisto de estrías transversales, mesonoto y propodeo foveado-reticulado, surco promesonotal fuertemente desarrollado, presencia de espinas propodeales. En vista dorsal, para ambas castas (soldado y la obrera) pospeciolo en forma de cono y en vista lateral en forma de trapecio. En vista lateral, peciolo y pospeciolo foveados, mientras que el gaster liso y brillante. Pilosidad densa y erecta en cabeza y gaster, escasa pilosidad erecta en el mesosoma. Color marrón rojizo a oscuro, apéndices claros.
Obrera. Medidas $(\mathrm{n}=5)$ : LC 0,60-0,77; AC 0,42-0,56; LE 0,69-0,77; LM 0,77-0.85; IC 60-85; IE 98-118. Cabeza, en vista dorsal, lisa y brillante, área entre fosa antenal y ojos costulada, margen occipital ancho, cuello nucal apenas perceptible, escapos largos (LE 0,69-0,77) que sobrepasan ampliamente el borde posterior. En vista lateral, pronoto completamente liso, mesonoto y propodeo foveados. En vista lateral, surco promesonotal fuertemente desarrollado, presencia de espinas propodeales. En vista lateral, peciolo y pospeciolo foveados. En vista lateral, gaster liso y brillante. Pilosidad dispersa y erecta en todo el cuerpo. Color marrón claro amarillento.

Variación morfológica. Se encontraron variaciones en la escultura del pronoto en las soldados dentro de la misma colonia, donde las carenas pueden ocupar completamente la superficie del pronoto o sólo ocurren en la región dorsal. Además, existen individuos (soldados y obreras) que exhiben una variación en la coloración desde marrón oscuro a marrón claro casi amarillento entre las diferentes colonias recolectadas en Taganga.

Biología. Esta especie invasora anida en el suelo, aun cuando el tipo de suelo es mayormente árido, las colonias están presentes en zonas de mayor arborización, también se han visto colonias en casas y cerca a zonas urbanas. Ambas castas forrajean comúnmente en el área, las obreras y soldados tienen hábitos totalmente epigeos y llegan fácilmente a una gran 

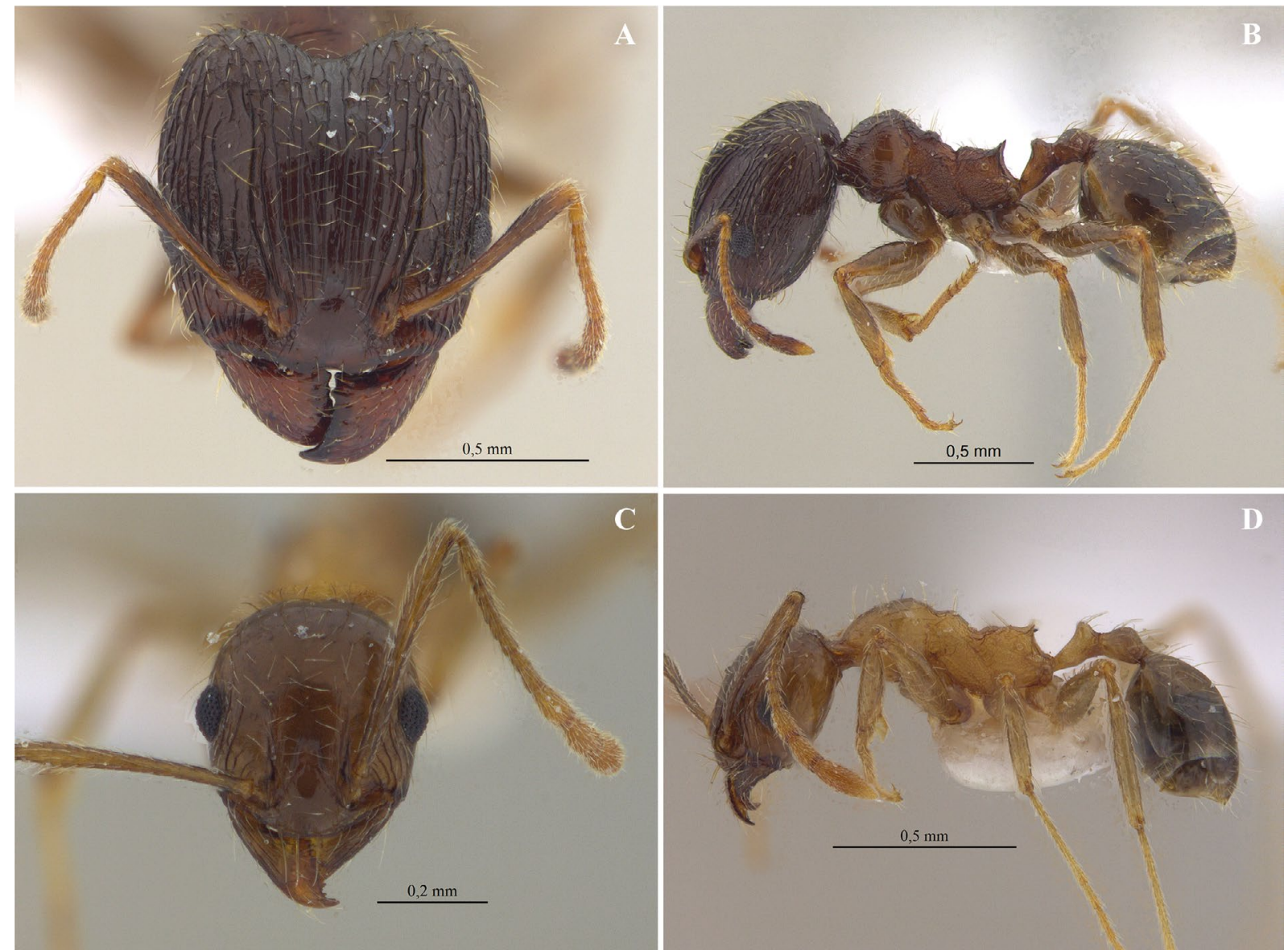

Figura 5. Hábito de la obrera de Pheidole indica Mayr, 1879. A. Cabeza en vista frontal de la soldado. B. Cuerpo en vista lateral de la soldado. C. Cabeza vista frontal de la obrera. D. Cuerpo en vista lateral de la obrera. Fotografías de soldado (CBUMAG:ENT11199) y obrera (CBUMAG:ENT11206) por R. J. Guerrero.

variedad de cebos que incluyen proteínas, sustancias azucaradas y frutos secos. Esta especie es dominante en términos de abundancia y desplaza rápidamente a otras especies de hormigas cercanas a su área de forrajeo.

Material examinado. 26 soldados, 19 obreras. COLOMBIA. Magdalena, Santa Marta, Taganga, $11^{\circ} 16^{\prime} 4,91^{\prime \prime} N$ $74^{\circ} 11^{\prime} 15,18^{\prime \prime} \mathrm{O}, 50 \mathrm{~m}$, captura manual, 27-sep- 2018. Camargo, J. [CBUMAG].

\section{Pheidole inversa Forel, 1901}

(Fig. 6)

Soldado. Medidas ( $\mathrm{n}=5)$ : LC 1,33-1,06; AC 0,96-1,17; LE 0,71-0,79; LM 0,87-1,08; IC 88-95; IE 59-69. Las soldados de $P$. inversa pueden ser reconocidas por presentar en vista dorsal, dos tercios anteriores de la cabeza costulados longitudinalmente, tercio posterior liso y brillante. En vista lateral región dorsal de la cabeza lisa y brillante. En vista lateral para ambas castas (soldado y obrera) convexidad mesonotal bien desarrollada, mesosoma, peciolo y pospeciolo foveados, mesosoma desprovisto de setas.

Franja foveoreticulada en el área entre los ojos de la superficie frontal de la cabeza. Margen hipostomal suavemente curvado, dientes hipostomales internos más próximos a los externos respecto a la línea media ventral de la cabeza. Escasa pilosidad apresada en la cabeza. En vista lateral, cóstulas en la región de la gena que apenas sobrepasan el ojo, región dorsal de la cabeza en vista lateral lisa y brillante. En vista dorsal pronoto foveado. En vista dorsal oblicua, pronoto redondeado. En vista lateral, mesosoma densamente foveado, presencia de surco promesonotal y espinas propodeales. En vista dorsal, al menos la mitad anterior de la superficie del primer terguito gastral áspera y opaca, con abundante pilosidad apresada. En vista lateral, gaster liso y brillante. Hormigas marrón claro y oscuro.

Obrera. Medidas ( $\mathrm{n}=5)$ : LC 0,63-0,75; AC 0,56-0,58; LE 0,69-0,79; LM 0,75-0,77; IC 76-88; IE 92-124. Cabeza, en vista dorsal, semicircular (IC 76-88), triangulo frontal liso. En vista dorsal cabeza densamente foveada. Escapos antenales largos que sobrepasan por mucho el borde posterior LE 0,69-0,79, margen occipital ancho sin cuello nucal. Escasa pilosidad apresada en la cabeza. En vista lateral, cabeza foveada y área de la gena costulada, cóstulas apenas llegan al ojo. En vista lateral, mesosoma foveado, presencia de surco promesonotal y espinas propodeales. En vista dorsal, dos tercios anteriores del primer terguito del gáster opaco. Gáster con pilosidad apresada. Hormigas de color negro.

Variación morfológica. Las soldados presentan variaciones de color desde individuos marrón claro a marrón oscuro con apéndices marrón claro; la variación es de tipo intra e intercolonial. 

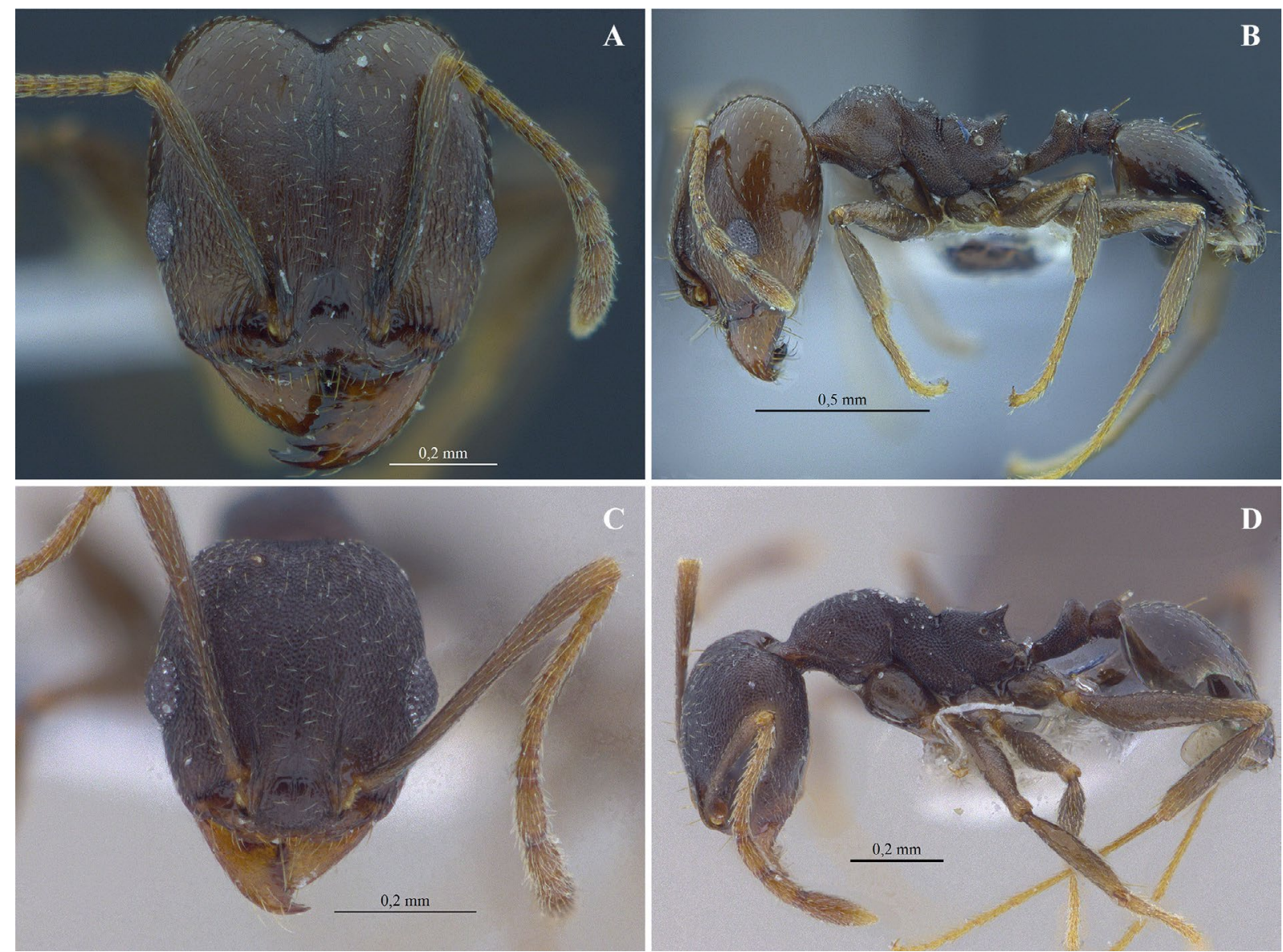

Figura 6. Hábito de Pheidole inversa Forel, 1901. A. Cabeza en vista frontal de la soldado. B. Cuerpo en vista lateral de la soldado. C. Cabeza en vista frontal obrera. D. Cuerpo en vista lateral de la obrera. Fotografías de soldado (CBUMAG:ENT11168) y obrera (CBUMAG:ENT11169) por R. J. Guerrero.

Biología. Esta especie anida en suelos principalmente arcillosos cerca de la montaña, aun cuando el tipo de suelo es en mayor proporción de tipo árido; las colonias están presentes en zonas de mayor arborización. También se observaron colonias de $P$. inversa cerca a zonas urbanas. Las soldados y obreras forrajean comúnmente en el suelo y ubican fácilmente los cebos, aprovechando el recurso en masa.

Material examinado. 1 soldado, 9 obreras. COLOMBIA. Magdalena, Santa Marta, Taganga, $11^{\circ} 15^{\prime} 32,98^{\prime \prime} \mathrm{N}$ $74^{\circ} 10^{\prime} 48^{\prime}$ 'O, $150 \mathrm{~m}$, captura manual, 1-mar-2007. Oliveros y Ramírez. [CBUMAG]. 11 soldados, 6 obreras. Magdalena, Santa Marta, Taganga, $11^{\circ} 16^{\prime} 4,91^{\prime \prime} \mathrm{N} 74^{\circ} 11^{\prime} 15,18^{\prime \prime} \mathrm{O}, 50 \mathrm{~m}$, captura manual, 23-sep-2018. Camargo, J. [CBUMAG].

\section{Pheidole leptina Wilson, 2003}

(Fig. 7)

Soldado. Medidas ( $\mathrm{n}=5$ ): LC 1,13-1,17; AC 1,02-1,12; LE 1,00-1,12; LM 1,08-1,15; IC 87-97; IE 85-98. Las soldados de $P$. leptina pueden ser reconocidas por presentar en vista dorsal cabeza relativamente pequeña que se estrecha hacia el margen occipital, superficie de la cabeza lisa y brillante con escapos largos que sobrepasan ampliamente el lóbulo posterior. En vista dorsal, pronoto liso. En vista lateral para ambas castas (soldado y obrera) convexidad mesonotal bien desarrollada, pronoto liso y brillante y espinas propodeales reducidas a dentículos.
Margen hipostomal con dos dientes hipostomales externos. En vista frontal, margen occipital estrecho, abundante pilosidad erecta y decumbente que se extiende lateralmente en la cabeza. En vista lateral, las cóstulas en la superficie de las genas apenas sobrepasan los ojos. En vista lateral, pronoto completamente liso, mesonoto y propodeo foveado; presencia de surco promesonotal. Pilosidad erecta y dispersa en todo el mesosoma. En vista lateral, peciolo y pospeciolo foveados. En vista lateral, gaster liso y brillante con dispersa pilosidad erecta. Color marrón oscuro.

Obrera. Medidas ( $\mathrm{n}=5$ ): LC 0,65-0,75; AC 0,38-0,48; LE 0,90-0,96; LM 0,77-0,94; IC 51-74; IE 121-147. Cabeza, en vista dorsal, alargada (IC 51-74), con superficie lisa y brillante, margen occipital estrecho con presencia de cuello nucal desarrollado. Escapos antenales largos (IE 121-147) que sobrepasan ampliamente el lóbulo posterior en vista frontal. Pilosidad erecta dispersa que se extiende hacia los lados de la cabeza. En vista lateral, pronoto liso y brillante, resto del mesosoma, peciolo y pospeciolo foveados. En vista lateral gaster liso y brillante. Cuerpo desprovisto de setas. Color marrón claro.

Variación morfológica. Tanto obreras como soldados presentaron variaciones de color desde individuos marrón claro con apéndices amarillo pardusco (Res. Biol. Caoba) a individuos de color marrón oscuro (Puerto Mosquito). También se encontraron variaciones en la escultura del pronoto de las soldados, presentando, en vista dorsal, carenas transversales 

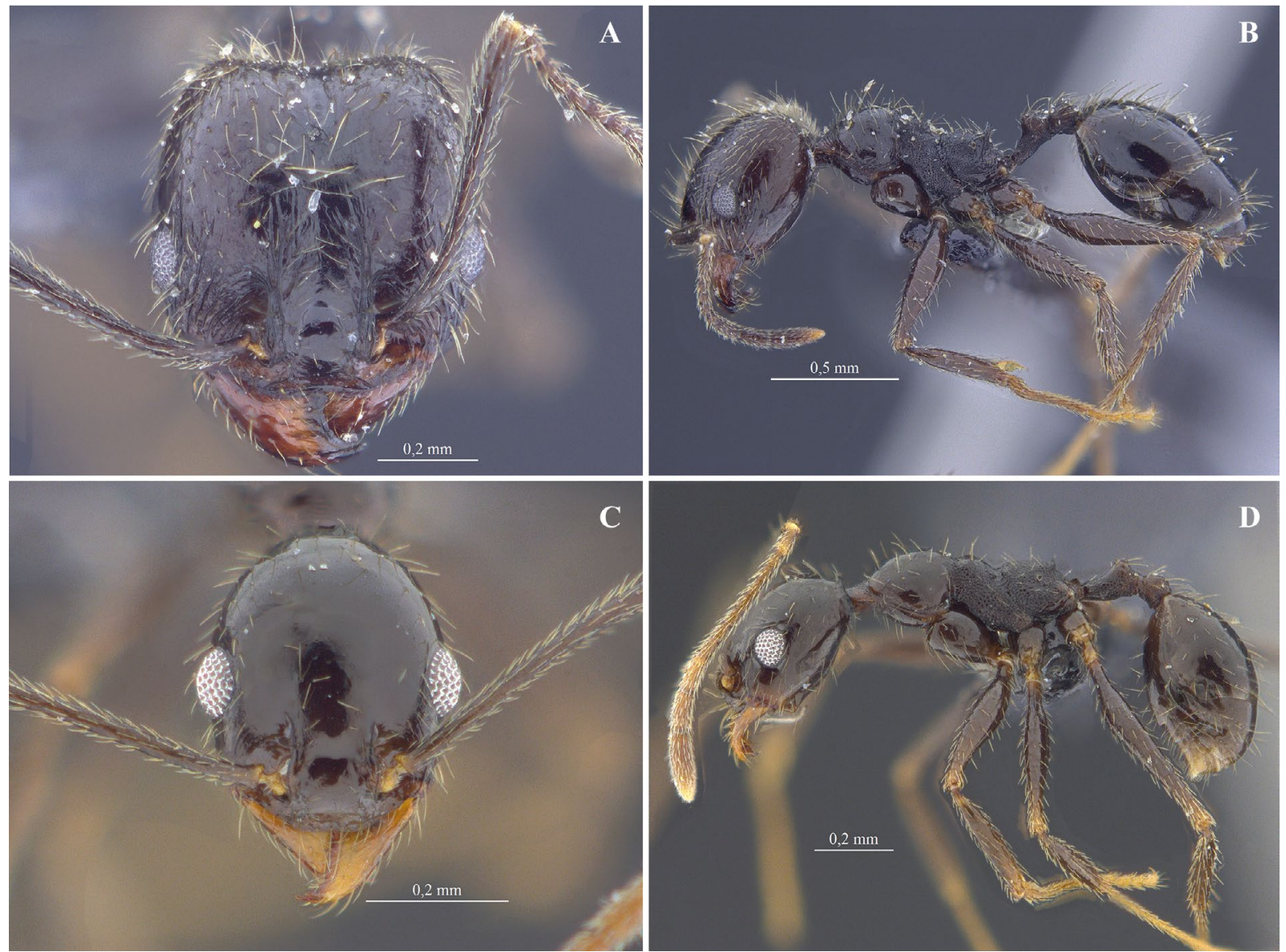

Figura 7. Hábito de la obrera de Pheidole leptina Wilson, 2003. A. Cabeza en vista frontal de la soldado. B. Cuerpo en vista lateral de la soldado. C. Cabeza vista frontal de la obrera. D. Cuerpo en vista lateral de la obrera. Fotografías de soldado (CBUMAG:ENT11184) y obrera (CBUMAG:ENT11188) por R. J. Guerrero.

fuerte o débilmente impresas en la parte más anterior del segmento, pero nunca ausentes; esta característica se observó en las poblaciones de la localidad de Puerto mosquito. Las soldados de $P$. leptina presentan una variación de tamaño mayor en relación con el tamaño registrado por Wilson (2003).

Biología. Esta especie anida en suelo descubierto en el borde del bosque cerca al río, aunque también se han observado cerca a zonas urbanas e incluso dentro de las casas. Las obreras llegan con mayor frecuencia al cebo que las soldados. Las obreras de $P$. leptina se ven fuertemente atraídas por sustancias azucaradas.

Material examinado. 6 soldados, 8 obreras. COLOMBIA. Magdalena, Santa Marta, Puerto Mosquito, $11^{\circ} 10^{\prime} 37,06^{\prime \prime} \mathrm{N}$ $74^{\circ} 11^{\prime} 6,611^{\prime \prime} \mathrm{O}, 50 \mathrm{~m}$, captura manual, 23-jun-2018. Camargo, J. [CBUMAG]. 1 soldado, 1 obrera. Magdalena, Reserva Biológica Caoba, $11^{\circ} 11^{\prime} 31,56^{\prime \prime} \mathrm{N} 74^{\circ} 5$ '59,99'O, 337 m, captura manual, 13-nov- 2018. Camargo, J. [CBUMAG].

\section{Pheidole pugnax Dalla Torre, 1892}

$$
\text { (Fig. 8) }
$$

Soldado. Medidas ( $\mathrm{n}=5)$ : LC 1,37-1,48; AC 1,42-1,56; LE 0,81-0,83; LM 1,29-1,37; IC 104-105; IE 56-59.

Las soldados de $P$. pugnax pueden ser reconocidas por presentar en vista dorsal mitad anterior de la cabeza costulada longitudinalmente, mitad posterior de la cabeza densamente foveada. En vista lateral mesosoma, peciolo y pospeciolo foveados. En vista dorsal pospeciolo en forma de cono. En vista dorsal tres cuartas partes del primer segmento del gaster y la franja central posterior del segundo densamente punteado, áspera.

Triangulo frontal liso y brillante, área entre el ojo y la fosa antenal rugoreticulada, bordes posteriores de la cabeza, suavemente redondeados. Margen hipostomal plano con cuatro dientes hipostomales, dientes hipostomales internos fuertemente afilados y más próximos a los dientes hipostomales internos respecto a la línea media ventral de la cabeza. Sin algún tipo de pilosidad en los márgenes laterales y posterior de la cabeza. En vista lateral, cóstulas en la superficie de la gena no alcanzan el ojo, parche liso y brillante en la mitad posterior de la cabeza. En vista dorsal, pronoto foveado. En vista lateral, todo el mesosoma cubierto de fóveas. Presencia de surco promesonotal y espinas propodeales fuertemente desarrolladas. Pilosidad dispersa y erecta en el mesosoma. En vista dorsal, pospeciolo en forma de cono. En vista lateral, gaster áspero y opaco. Color marrón rojizo y gaster negro.

Obrera. Medidas ( $\mathrm{n}=5)$ : LC 0,60-0,63; AC 0,54-0,56; LE 0,71-0,77; LM 0,75-0,77; IC 88-90; IE 112-129. Cabeza, en vista dorsal, semicuadrada (IC 88-90), y completamente foveada, escapos antenales largos que sobrepasan ampliamente el lóbulo posterior, margen occipital ancho, sin cuello nucal. Márgenes laterales de la cabeza con setas erectas dispersas. En vista lateral, mesosoma completamente foveado, presencia 

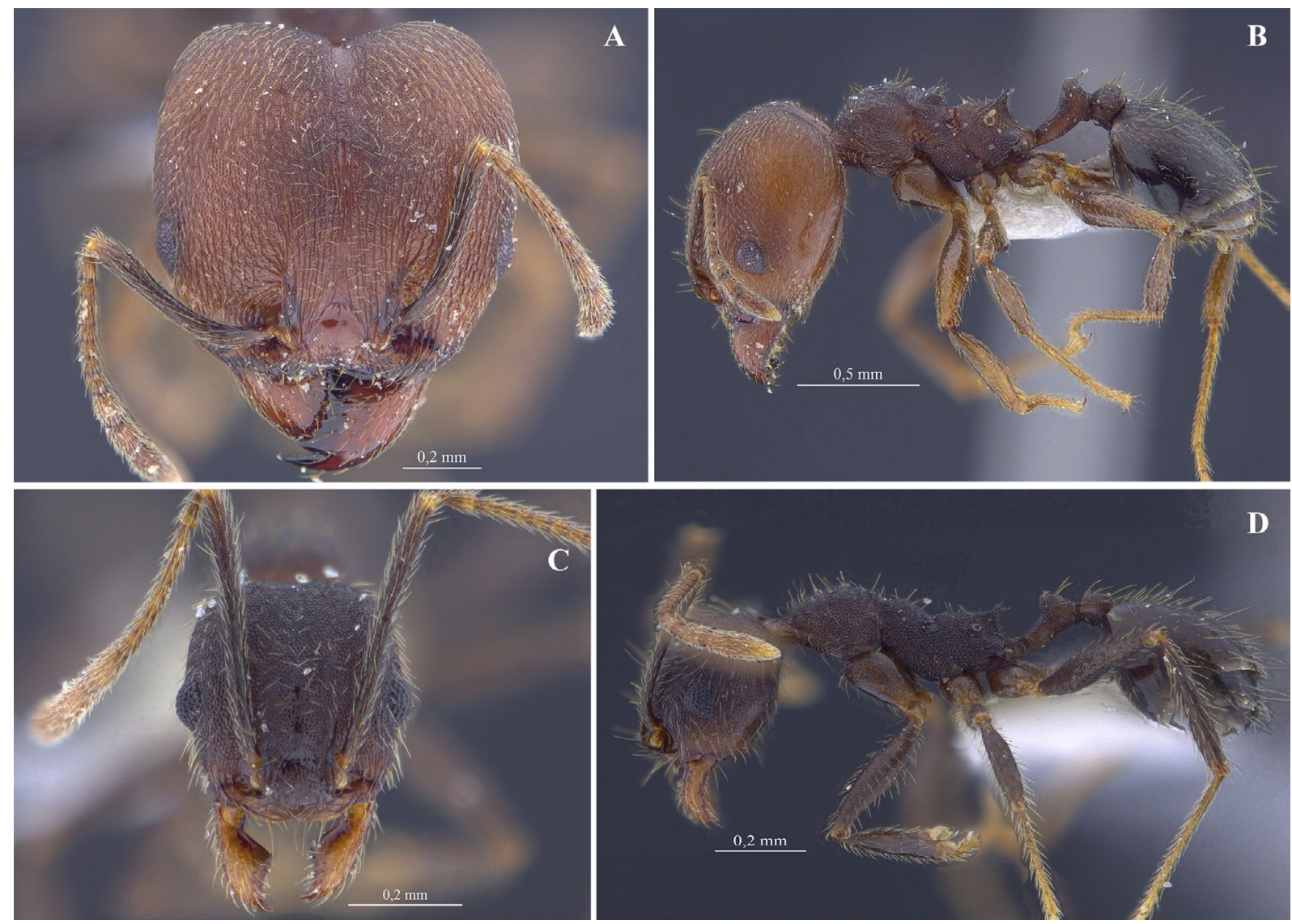

Figura 8. Hábito de Pheidole pugnax Dalla Torre, 1892. A. Cabeza en vista frontal de la soldado. B. Cuerpo en vista lateral de la soldado. C. Cuerpo en vista frontal de la obrera. D. Cuerpo en vista lateral de la obrera. Fotografías de soldado (CBUMAGENT11190) y obrera (CBUMAG:ENT11198) por R. J. Guerrero.

de espinas propodeales bien desarrolladas, presencia de setas erectas en el pronoto. En vista dorsal, primer y segundo segmento del gaster foveados. En vista lateral, región ventral del gaster lisa y brillante. Color negro.

Variación morfológica. Las soldados presentan variaciones de color desde marrón claro a amarillo parduzco con apéndices negros (Res. Biol. Caoba). Esta variación ya fue documentada por Wilson (2003) de poblaciones en Costa Rica.

Biología. Esta especie anida en suelo, sus colonias suelen ser numerosas (más de 300 individuos). Las obreras suelen forrajear en la vegetación mientras que las soldados son tímidos y salen poco del nido, sin embargo, pueden recolectarse ambas castas con cebos.

Material examinado. 23 soldados, 17 obreras. COLOMBIA. Magdalena, Santa Marta, Reserva Biológica Caoba,

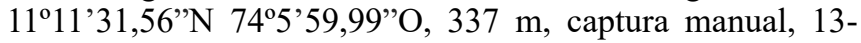
nov- 2018. Camargo, J. [CBUMAG].

\section{Pheidole radoszkowskii Mayr, 1884}

(Fig. 9)

Soldado. Medidas ( $\mathrm{n}=3$ ): LC 0,94-1,00; AC 0,94-0,96; LE 0,62-0,65; LM 0,60-0,85; IC 96-102; IE 62-69. Las soldados de $P$. radoszkowskii pueden ser reconocidas por presentar en vista dorsal cabeza, mesosoma, peciolo y pospeciolo densamente foveados. En vista frontal lóbulo frontal provisto de cóstulas longitudinales que alcanzan dos tercios de la cabeza. En vista dorsal oblicua, perfil del mesosoma de tres lóbulos bien diferenciados. En ambas castas poca pilosidad en el cuerpo y ausente en el mesosoma. En vista dorsal, para ambas castas (soldado y obrera), $1 / 4$ anterior del primer terguito del gáster con la superficie granulosa y opaca.

Cabeza, en vista dorsal, con cóstulas longitudinales en el lóbulo frontal apenas sobrepasan los ojos en vista frontal. Área entre el ojo y la fosa antenal rugoreticulada. Margen hipostomal suavemente curvado, dientes hipostomales internos más próximos a los externos respecto a la línea media ventral de la cabeza, ausencia de quinto diente hipostomal. Pilosidad casi ausente y apresada en la cabeza. En vista lateral, cabeza densamente foveada. En vista lateral, mesosoma foveado. Presencia de espinas propodeales. Pronoto desprovisto de setas. En vista lateral, peciolo y pospeciolo foveados. En vista dorsal, presencia de pelos decumbentes. Color marrón claro y oscuro.

Obrera. Medidas (n=3): LC 0,54-0,56; AC 0,40-0,46; LE 0,60-0,77; LM 0,63-0,67; IC 72-86; IE 110-138. Cabeza, en vista dorsal, completamente foveada, escapos largos que sobrepasan levemente el borde posterior (LE 0,60-0,77), margen occipital ancho sin cuello nucal. En vista lateral, cóstulas en la superficie de la gena no alcanzan el ojo, cabeza foveada. Hormigas de color negro y marrón oscuro.

Variación morfológica. En Puerto Mosquito, las soldados varían en color, desde completamente negros a marrón rojizo. 

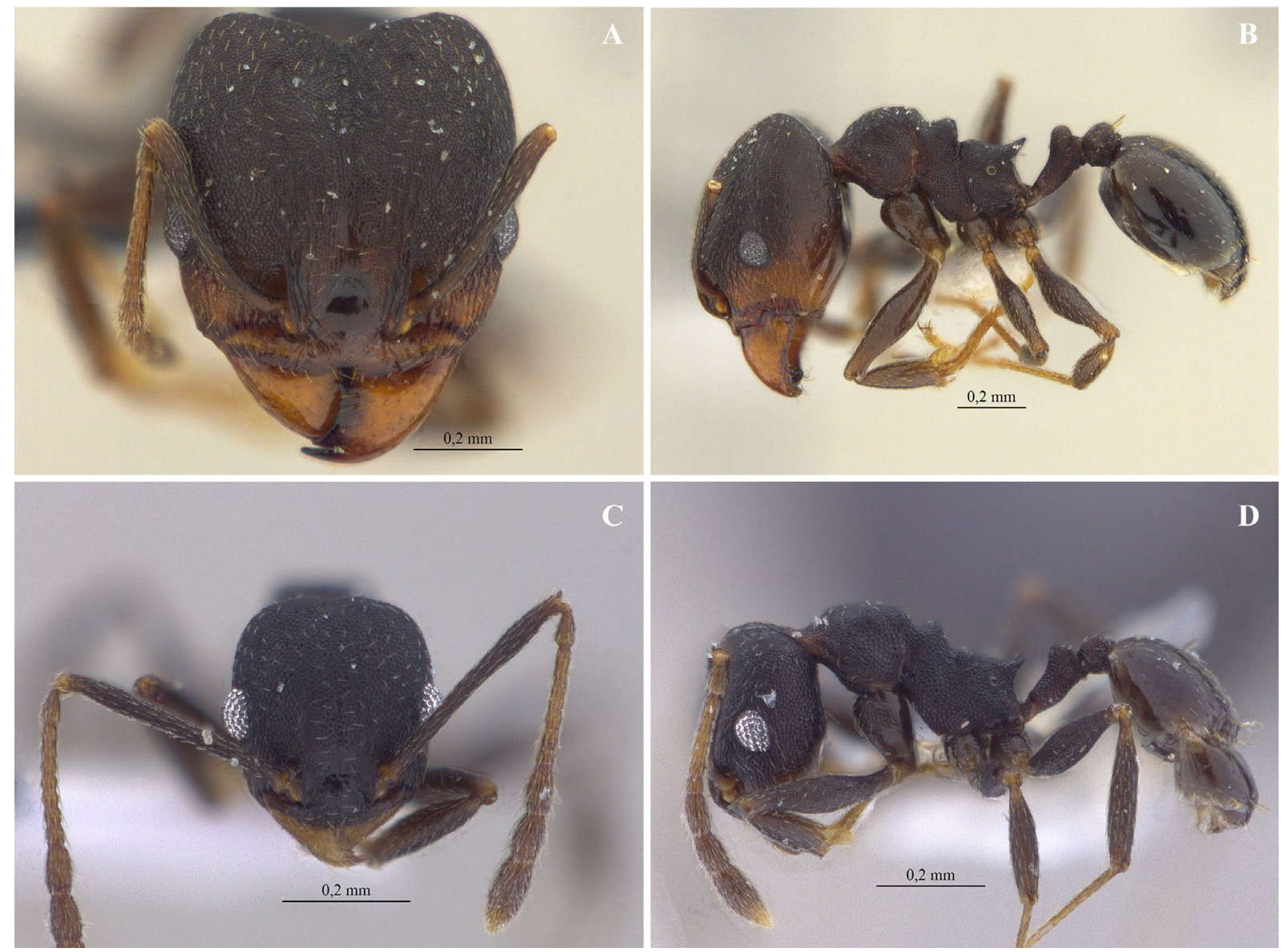

Figura 9. Hábito de la obrera de Pheidole radoszkowskii Mayr, 1884. A. Cabeza en vista frontal de la soldado. B. Cuerpo en vista lateral del soldado. C. Cabeza vista frontal de la obrera. D. Cuerpo en vista lateral de la obrera. Fotografías de soldado (CBUMAG: ENT11113) y obrera (CBUMAG:ENT11114) por R. J. Guerrero.

Así mismo, se encontraron variaciones en la escultura de la cabeza respecto a las cóstulas en el lóbulo frontal, las cuales puedes estar fuertemente impresas o apenas mostrarse en algunos pocos individuos dentro de y entre las colonias.

Biología. Esta especie habita en el suelo, en áreas descubiertas y principalmente húmedas. Las obreras y soldados forrajean generalmente cerca al nido.

Material examinado. 13 soldados, 8 obreras. COLOMBIA. Magdalena, Santa Marta, Puerto Mosquito, $11^{\circ} 10^{\prime} 37,06^{\prime \prime} \mathrm{N}$ $74^{\circ} 11^{\prime} 6,611^{\prime \prime} \mathrm{O}, 50 \mathrm{~m}$, captura manual, 26-jun-2018. Camargo, J. [CBUMAG].

\section{Pheidole reclusi Forel, 1899}

(Fig. 10)

Soldado. Medidas ( $\mathrm{n}=2)$ : LC 1,83-1,88; AC 1,56-1,58; LE 0,63-0,65; LM 1,38-1,40; IC 83-86; IE 35-37. Las soldados de $P$. reclusi pueden ser reconocidas por presentar en vista dorsal una densa escultura rugoretículada cubriendo el borde posterior y los márgenes laterales de la cabeza. En vista lateral, mitad anterior de la cabeza con fuerte convexidad limitada a la región media. Perfil promesonotal jorobado en vista lateral. En vista dorsal, un tercio anterior del primer terguito gastral provisto de estrías longitudinales, el resto liso.

Cabeza, en vista dorsal, grande y alargada (IC 83-86), escapos cortos y robustos (LE 0,63-0,65), apenas alcanzado el margen lateral de la cabeza por encima del ojo compuesto. Margen hipostomal fuertemente curvado con cinco dientes hipostomales, los dientes hipostomales internos están más próximos a los externos respecto a la línea media ventral de la cabeza. En vista lateral, mitad anterior de la cabeza con una extensa y fuerte concavidad, cabeza rugoreticulada. En vista lateral, la cara posterior del promesonoto cae casi verticalmente al metanoto. En vista lateral, superficie del mesosoma areolada-rugosa. En visa dorsal nódulo peciolar e inserción pospeciolar foveados, peciolo y pospeciolo areolado-rugoso. En vista lateral, gaster con superficie áspera. Todo el cuerpo con abundante pilosidad erecta. Color negro a marrón oscuro.

Obrera. Medidas $(\mathrm{n}=2)$ : LC 0,63-0,67; AC 0,65-0,71; LE 0,67-0,77; LM 0,77-0,79; IC 103-106; IE 100-121. Cabeza, en vista dorsal, semicuadrada (IC 103-106), superficie de la cabeza lisa y brillante, escapos largos que alcanzan el borde posterior, margen occipital estrecho. En vista lateral, pronoto y propodeo liso y brillante, mesonoto foveado. En vista dorsal-oblicua, húmero denticulado. Presencia de espinas propodeales cortas. En vista dorsal, primer terguito del gáster liso y brillante. Pilosidad dispersa y erecta en todo el cuerpo. Color marrón oscuro.

Variación morfológica. Las soldados y obreras mostraron uniformidad en características morfológicas, contrastante esto con la amplia variación en los caracteres morfométricos. 

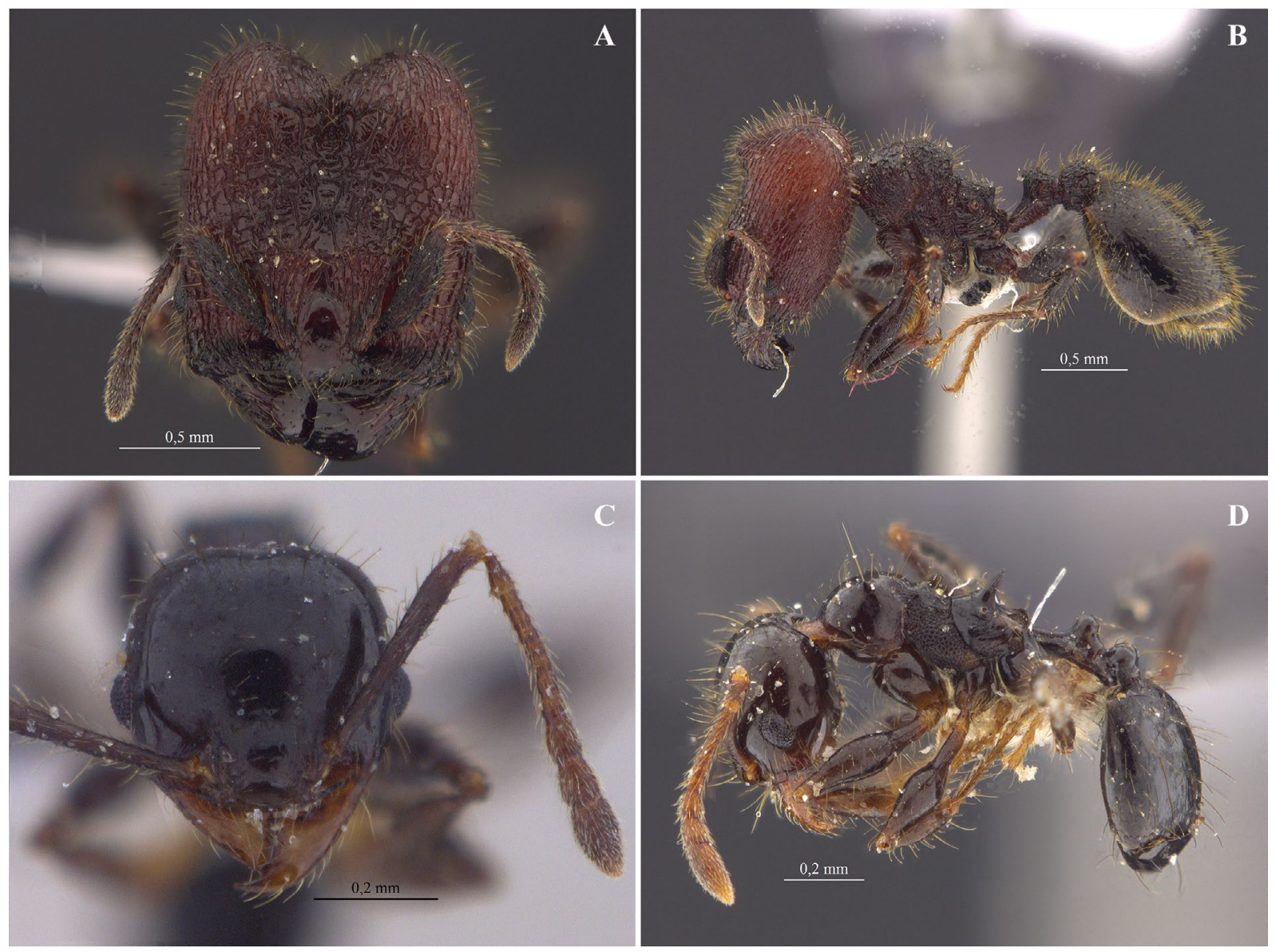

Figura 10. Hábito de Pheidole reclusi Forel, 1899. A. Cabeza en vista frontal de la soldado. B. Cuerpo en vista lateral de la soldado. C. Cabeza en vista frontal de la obrera. D. Cuerpo en vista lateral de la obrera. Fotografías de soldado (CBUMAG:ENT11100) y obrera (CBUMAG:ENT11102) por R. J. Guerrero.

Biología. Esta especie anida en suelos descubiertos mayormente húmedos. Las obreras forrajean comúnmente cerca al nido y llegan fácilmente a los cebos, mientras que las soldados son de hábitos totalmente hipogeos.

Material examinado. 2 soldados, 12 obreras. COLOMBIA. Magdalena, Santa Marta, Reserva Biológica Caoba,

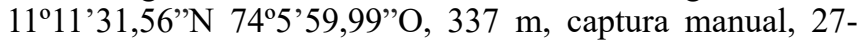
oct- 2018. Camargo, J. [CBUMAG].

\section{Pheidole steinheili Forel, 1901}

(Fig. 11)

Soldado. Medidas (n=5): LC 2,17-2,22; AC 2,12-2,18; LE 0,87-1,06; LM 1,60-1,67; IC 96-98; IE 39-48. Las soldados de $P$. steinheili pueden ser reconocidas por presentar en vista dorsal carenas que se originan cerca al tercio posterior de la línea media de la cabeza y que llegan al borde posterior, márgenes occipitales suavemente redondeados y salpicados con fóveas dispersas pero conspicuas. En vista dorsal todo el mesosoma, peciolo y pospeciolo transversalmente carinulados. Pospeciolo en vista dorsal en forma de cono.

En vista dorsal, cabeza grande, escapos cortos (IE 39-48). Margen hipostomal recto, con una fuerte depresión en la línea media ventral de la cabeza, cinco dientes hipostomales, dientes hipostomales internos más cerca de los dientes hipostomales externos que de la línea media. En vista lateral, presencia de carenas discontinuas que cubren la mayor parte de la mitad posterior de la cabeza. Pilosidad dispersa y apresada en la cabeza. En vista lateral, mesonoto y propodeo foveadoreticulados. En vista lateral, presencia de surco promesonotal y espinas propodeales, pilosidad erecta en el mesosoma. En vista lateral, peciolo y pospeciolo foveados. En vista dorsal, pospeciolo ancho y en forma de cono. En vista dorsal, mitad anterior del primer terguito del gaster con la superficie áspera. Gáster con abundante pilosidad apresada. Color negro.

Obrera. Medidas (n=5): LC 0,71-0,79; AC 0,62-0,75; LE 0,81-0,98; LM 0,94-1,06; IC 78-103; IE 111-124. Cabeza, en vista dorsal, lisa y brillante, escapos largos que sobrepasan ampliamente el borde posterior (IE 111-124). En vista frontal, margen occipital estrecho sin cuello nucal, pilosidad erecta y dispersa en la cabeza. En vista lateral, pronoto totalmente liso y brillante, mesonoto y propodeo foveado-reticulado. Presencia de surco promesonotal y espinas propodeales, pilosidad erecta y dispersa todo el mososoma. En vista lateral, peciolo y pospeciolo foveados. En vista lateral, gaster liso y brillante con pilosidad erecta y dispersa. Color negro.

Variación morfológica. La mayor variabilidad se presentó en el color. Las colonias pueden contener tanto obreras como soldados de color marrón claro (esclerotización completa) a completamente marrón oscuro.

Biología. Esta especie anida en suelo descubierto en el borde del bosque cerca al río. Sus obreras son epigeas, aunque son 

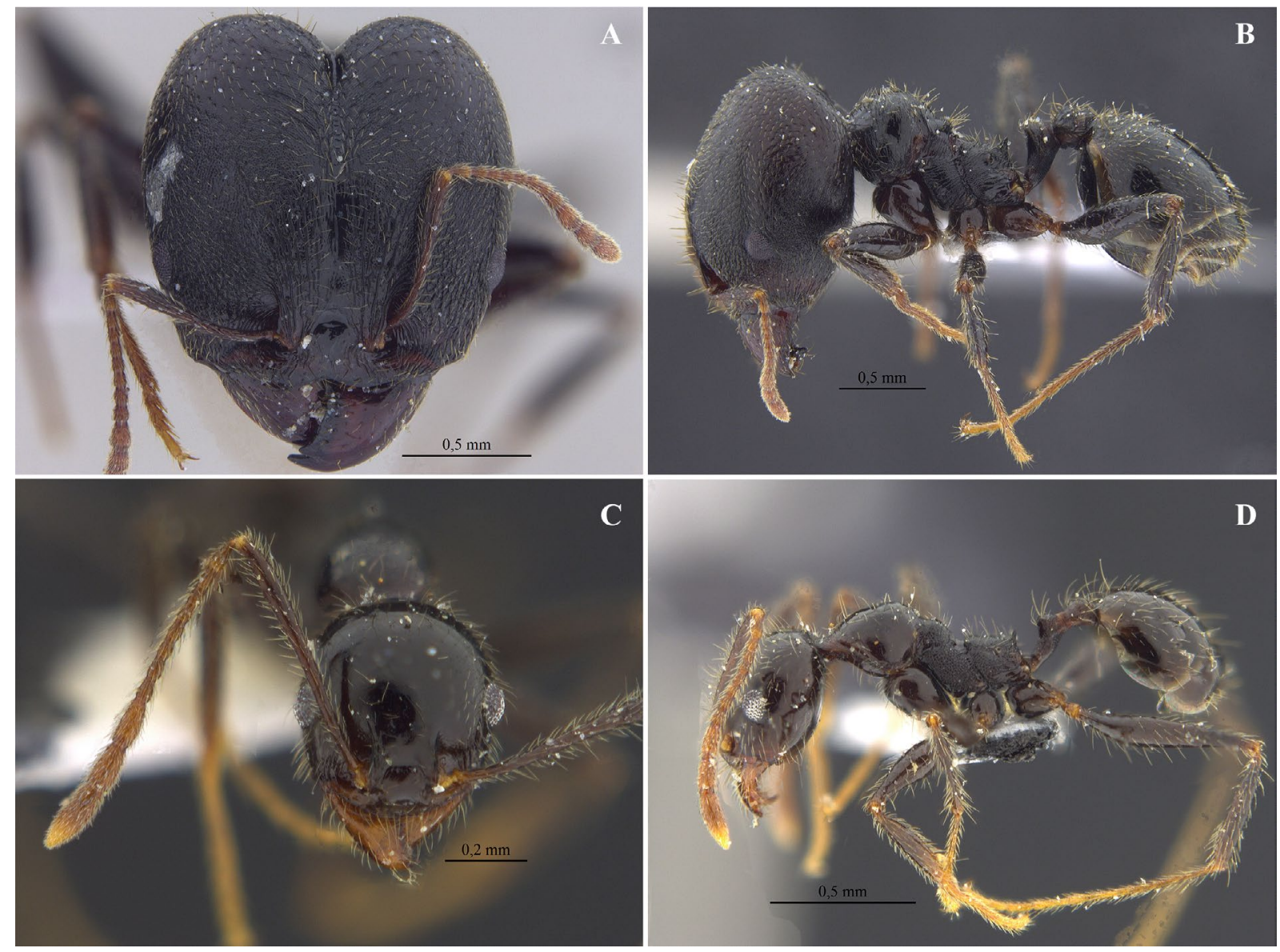

Figura 11. Hábito de la obrera de Pheidole steinheili Forel, 1901. A. Cabeza en vista frontal de la soldado. B. Cuerpo en vista lateral de la soldado. C. Cabeza vista frontal obrera. D. Cuerpo en vista lateral de la obrera. Fotografías de soldado (CBUMAG:ENT11104) y obrera (CBUMAG:ENT11107) por R. J. Guerrero.

más comunes en el suelo y ocasionalmente se pueden recolectar las soldados en cebos. Estos últimos responde rápidamente a la perturbación del nido.

Material examinado. 15 soldados, 10 obreras. COLOMBIA. Magdalena, Santa Marta, Puerto Mosquito, $11^{\circ} 10^{\prime} 37,06^{\prime \prime} \mathrm{N}$ $74^{\circ} 11^{\prime} 6,611^{\prime \prime} \mathrm{O}, 50 \mathrm{~m}$, captura manual, 23-jun-2018. Camargo, J. [CBUMAG].

\section{Pheidole subarmata Mayr, 1884}

(Fig. 12)

Soldado. Medidas ( $\mathrm{n}=5)$ : LC 1,04-1,19; AC 0,81-0,94; LE 0,44-0,50; LM 0,77-0,96; IC 78-80; IE 41-44. Las soldados de $P$. subarmata pueden ser reconocidos por presentar en vista dorsal cabeza alargada, cóstulas longitudinales que ocurren desde el lóbulo frontal y que alcanzan la mitad anterior de la cabeza, mitad posterior lisa y brillante. Los lóbulos frontales sobresalen de forma triangular en vista lateral. En vista lateral promesonoto redondeado, espinas propodeales reducidas a dentículos. Cabeza, mesosoma y gaster mayormente lisos y brillantes.

Margen hipostomal suavemente curvado, dientes hipostomales internos más próximos a la línea media respecto a los dientes hipostomales externos, presencia de un quinto diente hipostomal. Pilosidad dispersa y apresada en la cabeza. En vista lateral, las cóstulas en el área de la gena apenas sobrepasan el ojo. En vista lateral, región dorsal de la cabeza lisa y brillante. En vista lateral, perfil promesonotal fuertemente convexo, mesosoma totalmente liso y brillante, espinas propodeales reducidas a dentículos. Pilosidad dispersa y erecta en el mesosoma. En vista lateral, región dorsal del peciolo y pospeciolo liso y brillante, región ventral foveada. Gaster liso y brillante, con abundante pilosidad apresada en vista lateral. Color negro y marrón claro, apéndices amarillos.

Obrera. Medidas ( $\mathrm{n}=5)$ : LC 0,38-0,48; AC 0,40-0,44; LE 0,42-0,48; LM 0,52-0,58; IC 88-105; IE 96-110. Cabeza, en vista dorsal, lisa y brillante, escapos antenales largos que sobrepasan ampliamente el borde posterior (LE 0,42-0,48), margen occipital ancho sin presencia de cuello nucal, pilosidad dispersa y erecta. En vista lateral, cabeza lisa y brillante. En vista dorsal oblicua, pronoto fuertemente convexo. Pilosidad erecta y dispersa en el mesosoma. Espinas propodeales reducidas a dentículos. En vista lateral, peciolo, pospeciolo y gáster lisos y brillantes. Abundantes setas erectas en el gáster. Color amarillo.

Variación morfológica. Tanto obreras como soldados presentan variaciones de color desde individuos marrón claro en la localidad de Caoba a individuos completamente negros en Puerto Mosquito. Así mismo, dentro de las colonias tanto en Puerto Mosquito como en Caoba, las obreras presentan variaciones en la escultura de la mitad posterior de la cabeza; en algunos individuos la porción de la cabeza es completamente lisa y brillante mientras que otros solamente la mitad dorsal posterior. 

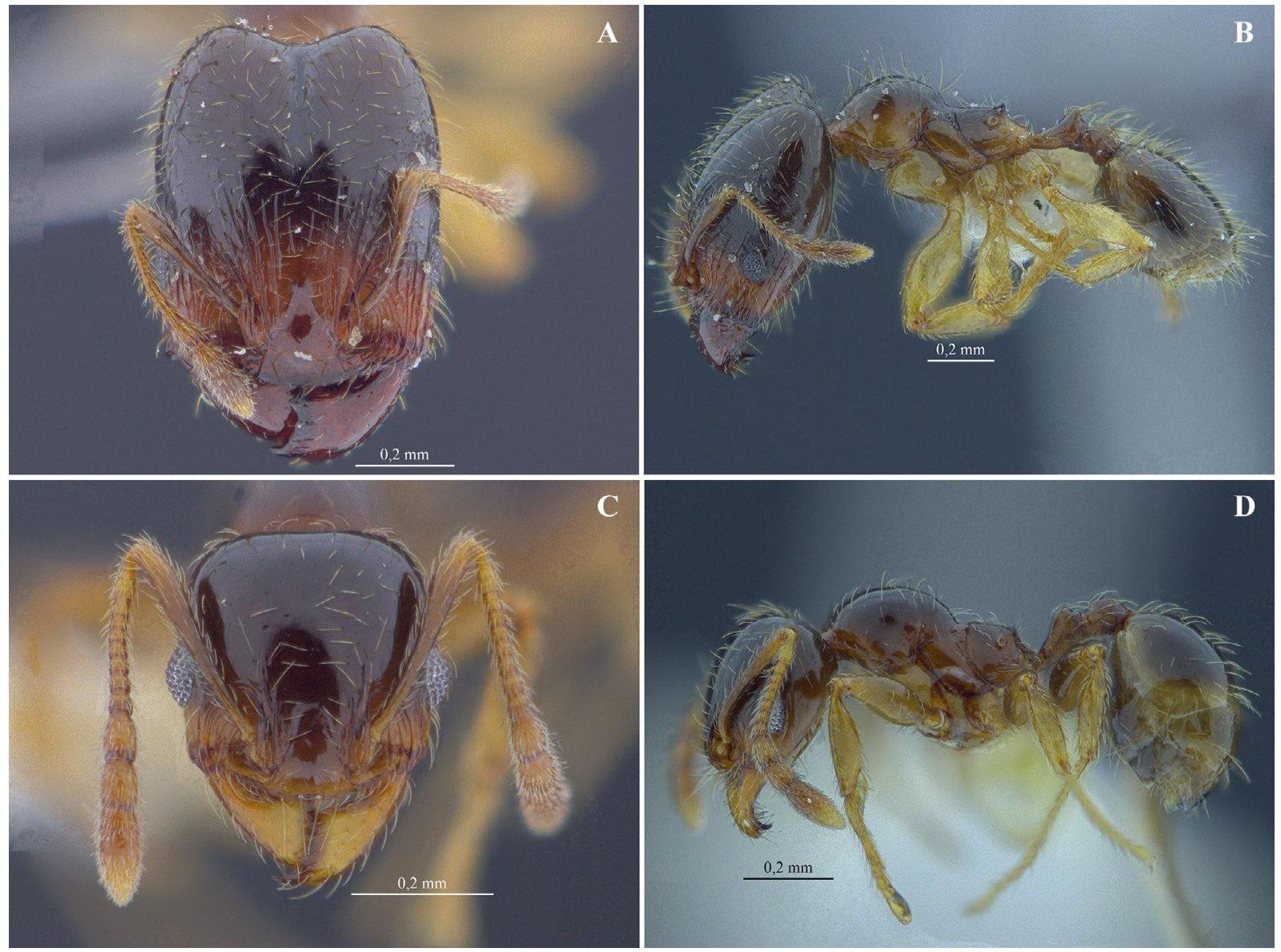

Figura 12. Hábito de Pheidole subarmata Mayr, 1884. A. Cabeza en vista frontal de la soldado. B. Cuerpo en vista lateral de la soldado. C. Cabeza en vista frontal de la obrera. D. Cuerpo en vista lateral de la obrera. Fotografías de soldado (CBUMAG:ENT11129) y obrera (CBUMAG:ENT11138) por R. J. Guerrero.

Biología. Esta especie anida en el suelo ya sea en el margen del bosque ribereño o al interior en áreas densamente boscosa; también fue encontrada en la hojarasca y siempre asociada a hábitats relativamente húmedos. Las obreras forrajean comúnmente en el área mientras que las soldados presentan hábitos mayormente hipogeos. La entrada del nido es excesivamente pequeña, muy parecida a los nidos de $P$. guajirana y $P$. transversostriata.

Material examinado. 6 soldados, 14 obreras. COLOMBIA. Magdalena, Santa Marta, Puerto Mosquito, $11^{\circ} 10^{\prime} 37,06^{\prime \prime} \mathrm{N}$ $74^{\circ} 11^{\prime} 6,611^{\prime \prime} \mathrm{O}, 50 \mathrm{~m}$, captura manual, 23-jun-2018. Camargo, J. [CBUMAG]. 16 soldados, 26 obreras. Magdalena, Santa Marta, Reserva Biológica Caoba, $11^{\circ} 11^{\prime} 31,56^{\prime \prime} \mathrm{N}$ 74'5'59,99'O, 337 m, captura manual, 27-oct-2018. Camargo, J. [CBUMAG].

\section{Pheidole transversostriata Mayr, 1887}

(Fig. 13)

Soldado. Medidas ( $\mathrm{n}=3$ ): LC 0,79-0,83; AC 0,60-0,67; LE 0,310,35; LM 0,58-0,60; IC 74-76; IE 39-42. Las soldados de $P$. transversostriata pueden ser reconocidos por presentar en vista dorsal cabeza alargada, amplia serie de carenas transversales que alcanzan tres cuartos de la cabeza; espacio entre esas cóstulas liso y brillante. Lóbulos posteriores de la cabeza rugoreticulados. En vista lateral, mitad ventroposterior de la cabeza lisa y brillante. En vista dorsal pronoto carinulado transversalmente.
En vista lateral para ambas castas (soldado y obrera) mesosoma, peciolo y pospeciolo principalmente foveados.

Cabeza, en vista frontal, con escapos antenales cortos (IE 39-42) y escrobos antenales bien diferenciados. Margen hipostomal suavemente curveado con cinco dientes hipostomales, dientes hipostomales internos más próximos de los externos que a la línea media ventral de la cabeza. Pilosidad dispersa y erecta en la cabeza. En vista lateral, peciolo y pospeciolo foveado. Pilosidad dispersa y erecta en el mesosoma. En vista lateral, gaster liso y brillante con abundantes setas erectas. Hormigas de color marrón amarillento.

Obrera. Medidas ( $\mathrm{n}=3$ ): LC 0,37-0,40; AC 0,35-0,37; LE 0,35-0,40; LM 0,38-0,44; IC 90-95; IE 95-100. Cabeza, en vista dorsal, densamente foveada, escapos antenales apenas alcanzando el borde posterior (IE 95-100), margen occipital ancho sin cuello nucal. En vista lateral, superficie de la gena costulada, mitad posterior de la cabeza lisa y brillante. En vista lateral, mesosoma totalmente foveado, ausencia de surco promesonotal, presencia de espinas propodeales reducidas a dentículos. En vista dorsal, nódulo peciolar liso y brillante. En vista lateral, peciolo y pospeciolo foveado. En vista lateral, gaster liso y brillante. Todo el cuerpo con escasa pilosidad erecta y discontinua, más abundante hacia los tergos del gáster. Hormiga marrón amarillento a marrón rojizo.

Variación morfológica. Las soldados presentan variación en la escultura de la cara ventral de la cabeza: en la mayoría de 

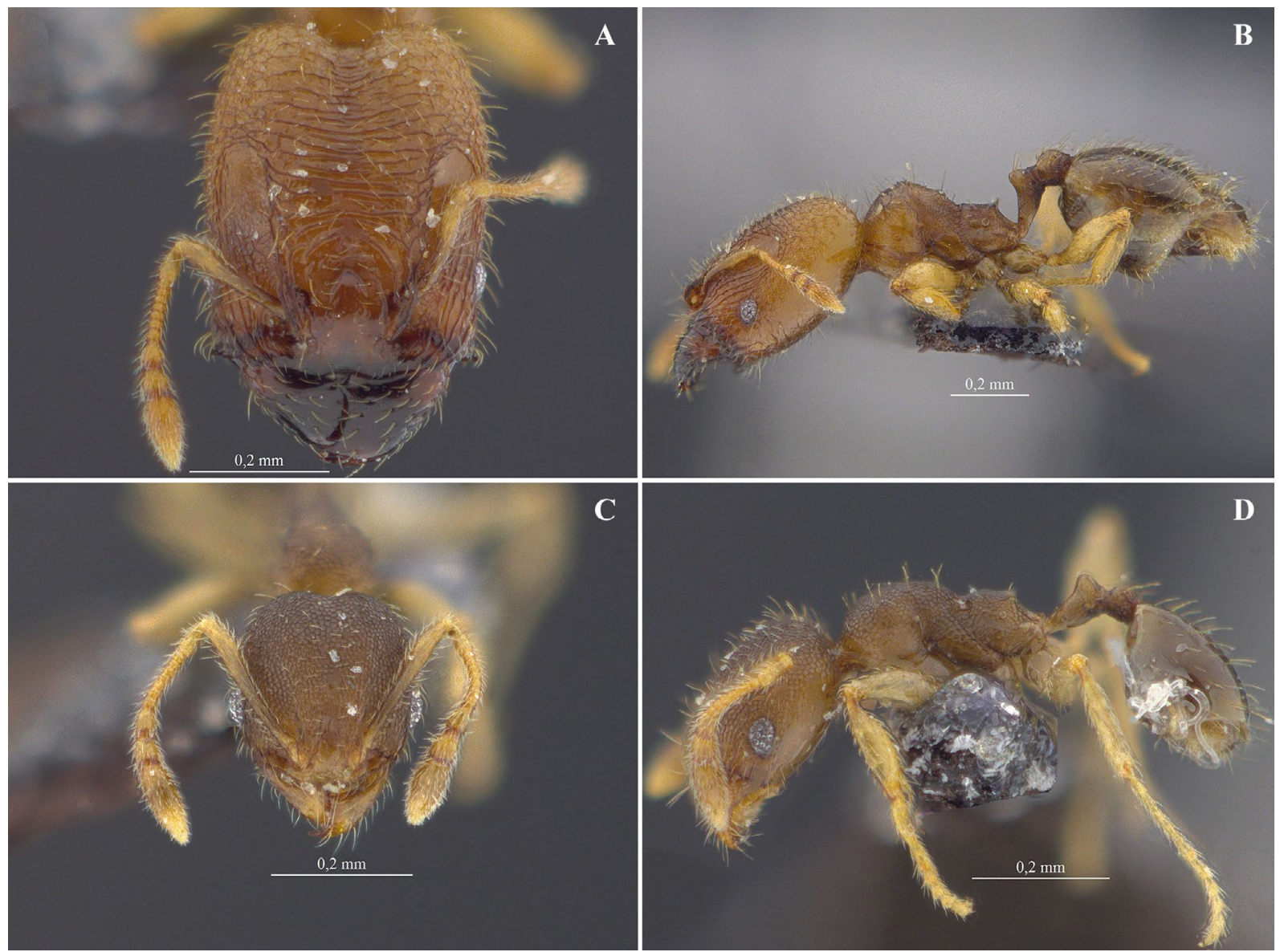

Figura 13. Hábito de Pheidole transversostriata Mayr, 1887. A. Cabeza en vista frontal de la soldado. B. Cuerpo en vista lateral de la soldado. C. Cabeza en vista frontal de la obrera. D. Cuerpo en vista lateral de la obrera. Fotografías de soldado (CBUMAGENT11124) y obrera (CBUMAG:ENT11127) por R. J. Guerrero.

especímenes de la serie (13 soldados) del mismo nido se presentan estrías transversas fuertemente marcadas extendiéndose hacia los márgenes laterales, pero en tres ejemplares las estrías se difuminan hacia los márgenes laterales de la cabeza. Las obreras pueden variar de marrón amarillento a marrón rojizo, pero nunca amarillas.

Biología. Esta especie anida en el suelo en áreas descubiertas de hojarasca, troncos o ramas secas. La entrada del nido es excesivamente pequeña, muy parecida a los nidos de $P$. subarmata y $P$. guajirana. Las obreras se encuentran comúnmente forrajeando y llegan fácilmente a los cebos, mientras que las soldados tienen hábitos totalmente hipogeos.

Material examinado. 5 soldados, 8 obreras. COLOMBIA. Magdalena, Santa Marta, bosque seco de la Universidad del Magdalena, $11^{\circ} 13^{\prime} 17,58^{\prime \prime} \mathrm{N} 74^{\circ} 11^{\prime} 10,86^{\prime \prime} \mathrm{O}, 30 \mathrm{~m}$, captura manual, 12-sep- 2018. Camargo, J. [CBUMAG].

\section{Pheidole urbana $\mathrm{n}$. sp.}

http://zoobank.org/urn:lsid:zoobank.org:act:78A3910F2C7F-4811-B8CB-2CAFE9F3EF3A

(Fig. 14)

Material tipo. Pheidole urbana n. sp. HOLOTIPO. 1 soldado. COLOMBIA. Magdalena, Santa Marta, Taganga, $11^{\circ} 16^{\prime} 4,91^{\prime \prime} \mathrm{N} 74^{\circ} 11^{\prime} 15,18^{\prime \prime} \mathrm{W}, 50 \mathrm{~m}$, captura manual, 23-sep2018. Camargo, J. [CBUMAG12810]. PARATIPOS (4 solda- dos y 5 obreras, con códigos consecutivos CBUMAG12811 - CBUMAG12819). Datos iguales al holotipo.

Medidas del Holotipo: LC 1,07; AC 0,98; LE 0,61; LM 0,82; IC 92; IE 57.

Diagnosis. Con el perfil morfológico generalizado de P. amabilis Wilson, 2003, P. arhuaca Wilson, 2003 y P. boliviana Wilson, 2003, y con un perfil métrico concordante con el de las especies del grupo informal "flavens" incluyendo el de $P$. amabilis, pero relativamente mayor que el de $P$. arhuaca y $P$ boliviana Wilson, 2003. Obrera: Ocho pelos aplanados y ensanchados en el ápice, ubicados en el dorso del promesonoto, contrastando con los pelos largos y cilíndricos en $P$. arhuaca y los abundantes pelos mucho más largos y delgados en $P$. amabilis y $P$. boliviana; proyecciones triangulares en el propodeo dirigidas oblicuamente hacia afuera, las cuales difieren de las espinas propodeales conspicuas en las obreras de las tres especies. Soldado: Clípeo con una muesca profunda en el centro del margen anterior, diferente al margen anteroclipeal recto en $P$. amabilis, $P$. arhuaca y suavemente cóncavo en $P$. boliviana. En vista dorsal, rostro con una combinación de carínulas longitudinales laterales de longitudes desiguales formando un contorno cóncavo con respecto al conjunto de carínulas longitudinales centrales que se extienden hasta la mitad de la longitud cefálica, contrastando con las carínulas en $P$. amabilis escasas y muy separadas entre sí, apenas alcanzando el primer tercio anterior de la longitud cefálica, mientras que las 
de $P$. arhuaca y $P$. boliviana son relativamente más gruesas, distantes entre sí, y sobrepasan la mitad de la longitud cefálica; vértice posterior cefálico fuertemente lobulado, con una concavidad amplia y profunda, relativamente similar en $P$. boliviana, pero contrastante con el perfil ligeramente cóncavo en $P$. amabilis y $P$. arhuaca (rasgo variable entre estas especies). Propodeo armado con proyecciones triangulares cortas, tan largas como anchas, diferentes a las espinas cortas pero agudas tanto en $P$. amabilis (dirigidas hacia arriba), P. arhuaca y en $P$. boliviana (en estas dos últimas dirigidas hacia atrás). Pospeciolo trapezoidal, más ancho que largo, con el margen anterior convexo, contrastante con el pospeciolo ovalado en las tres especies. Línea de pelos erectos largos y puntiagudos esparcidos sobre el dorso del margen posteriorcefálico y el área central del dorso de la cabeza; el resto de la cápsula cefálica con pelos recostados, contrastado con la pilosidad larga y erecta en todo el dorso y margen posterior de la cabeza de P. amabilis (relativamente diferente a las otras especies en comparación), $P$. arhuaca y P. boliviana. Promesonoto con pocos pelos erectos, concentrados principalmente en el pronoto, contrastando con los abundantes pelos erectos y semierectos en el promesonoto de $P$. amabilis, $P$. arhuaca y $P$. boliviana (más abundantes y largos en esta última). Margen dorsal de la tibia de la pata posterior con pelos largos recostados, nunca semierectos como en $P$. amabilis y $P$. arhuaca o combinación de erectos largos y semierectos cortos como en $P$. boliviana. Color marrón rojizo muy oscuro relativamente similar al encontrado en $P$. boliviana, pero contrastante con el amarillo uniforme de $P$. amabilis y P. arhuaca.

Descripción de la soldado. Medidas (Paratipos, $\mathrm{n}=4$ ) LC 1,07-1,15; AC 0,94-1,03; LE 0,54-0,62; LM 0,82-0,90; IC 83-92; IE 47-58.

Mandíbulas lisas y brillantes, tan anchas como largas, con un gran diente apical triangular que se abre del resto del margen masticador liso por una incisión amplia. Clípeo carinulado y aplanado. Escapos cortos, apenas alcanzando la mitad del largo de la cabeza; máxima amplitud cerca al ápice. Ojos compuestos ligeramente aplanados, ubicados por debajo del primer tercio anterior de la cabeza. En vista dorsal, cabeza más larga que ancha, con los márgenes laterales paralelos, semiparalelos a ligeramente convexos, cuando esto último, máxima amplitud apenas por encima del margen superior de los ojos compuestos; en perfil, cabeza inflada antero dorsalmente y con una depresión amplia hacia la región posterior, cara ventral aplanada; superficie dorsal de la cabeza con carínulas longitudinales distribuidas en un parche central que corre desde las carenas frontales y se difuminan hacia la mitad del largo de la cabeza, carínulas longitudinales rodeando los ojos compuestos y extendiéndose posteriormente, muy por debajo de la máxima longitud de las carínulas centrales; entre ambas regiones carinuladas superficie con carínulas finas y difuminadas, imperceptibles en aumento menor a 96X, dando la impresión de una superficie lisa y opaca; área posterodorsal de la cabeza lisa y brillante; cara ventral completamente lisa. Margen hipostomal recto; cinco dientes hipostomales, dientes hipostomales internos fuertemente afilados y más próximos a los dientes hipostomales externos respecto a la línea media, diente hipostomal medio apenas sobresaliendo en una pequeña protuberancia triangular. Línea media ventral de la cabeza con pelos erectos desde el foramen hasta el margen hipostomal, el resto de la superficie con pelos recostados relativamente más largos que los dorsales. Pronoto, visto oblicuamente, con húmeros angulados pronunciados. En perfil, surco promesonotal marcado como una leve depresión que se continua en una cara plana y posteriormente cae en una cara recta. Propodeo con la cara dorsal recta a suavemente cóncava. En vista dorsal, cara anterior del pronoto con densas cóstulas transversas que se extienden lateralmente como carínulas concéntricas dirigidas hacia la esquina humeral. Dorso del peciolo en vista posterior, recto a levemente deprimido hacia el centro, con las esquinas redondeadas continuándose en los márgenes laterales rectos y paralelos. Pospeciolo con una depresión inferolateral por detrás del margen anterior. En vista lateral, mesonoto, propodeo, peciolo y pospeciolo densamente foveado. Promesonoto con cuatro pelos notablemente más largo que el resto; propodeo con o sin un par de pelos muy cortos; peciolo y pospeciolo con pelos erectos largos curvados y dirigidos hacia atrás; primer terguito del gáster tenuemente imbricado, con abundantes pelos largos semierectos, gruesos y romos en la punta.

Descripción de la obrera. Medidas (Paratipos, $\mathrm{n}=5$ ): LC 0,51-0,54; AC 0,42-0,48; LE 0,51-0,56; LM 0,56-0,60; IC 81-91; IE 100-107.

Mandíbulas con carínulas finas y tenues en el margen externo extendiéndose hasta la mitad de cara dorsal, superficie lisa y brillante de la mitad de la cara dorsal hacia el margen masticador. Clípeo estrecho con una leve depresión central y rúgulas en el dorso de la placa. En vista frontal, superficie de la cabeza áspera y opaca, con gránulos muy finos y rugoreticulaciones; rostro con seis carínulas semiconcéntricas alrededor de las inserciones antenales, finas rúgulas longitudinales por debajo y frente al ojo compuesto, estas últimas extendiéndose tenuemente hasta la mitad del dorso de la cápsula cefálica; superficie de la posgena rugoreticulada cerca al occipucio, con rúgulas oblicuas extendiéndose hacia el centro, superficie lisa por encima del hipostoma. Margen posterior cefálico recto a levemente deprimido mesalmente, sin presencia de cuello nucal. Escapo finamente punteado, con abundantes pelos recostados cortos y semierectos largos, estos últimos más cortos que la mitad del máximo ancho del escapo. Promesonoto suavemente convexo, con una sutura promesonotal marcada. En perfil, cara dorsal del propodeo recta, extendiéndose posteriormente para formar unas prolongaciones triangulares proyectadas oblicuamente hacia afuera. Pronoto débil a fuertemente areolado en los lados, con rúgulas transversas anteriormente; katepisterno, lados y cara dorsal del propodeo. Dorso del promesonoto con ocho pelos aplanados, anchos distalmente, ubicados en el margen entre la cara dorsal y los lados, los cuatro anteriores relativamente más largos que los posteriores. Margen dorsal de la tibia con pelos largos completamente recostados. Lados del peciolo y pospeciolo fuertemente aerolado, con dos y cuatro pelos ubicados en el dorso del peciolo y pospeciolo, respectivamente. Primer tergo gastral opaco, tenuemente imbricado, con pelos largos semierectos gruesos y romos en la punta, muy espaciados entre sí, algunos pelos cortos recostados distribuidos entre los pelos largos. Color marrón amarillento a marrón rojizo oscuro.

Variación morfológica y comentarios. Las soldados de las poblaciones de Taganga son completamente negras, contrastando con las variaciones de coloración marrón claro rojizo en las poblaciones que habitan relictos de bosque seco al oriente de Santa Marta. Las poblaciones en Taganga también presentan variación en la longitud de las cóstulas de la gena en vista lateral, extendiéndose hasta la mitad de la cabeza o apenas sobrepasando el ojo; esta variación se observó dentro de un mismo nido recolectado en el sitio. 
Pheidole urbana comparte el espacio morfométrico con las especies $P$. amabilis, $P$. arhuaca y $P$. boliviana (ver Diagnosis para diferencias morfológicas), pero $P$. urbana podría confundirse con $P$. bilimeki Mayr, 1870 (complejo bilimeki sensu Longino y Cox (2009)), sobre todo en la morfología de las obreras y algunos rasgos con las soldados. Según Longino y Cox (2009) P. bilimeki es muy común en el norte de América del Sur, por lo tanto, es importante generar información que permita discernir entre estas dos especies. Aunque en este trabajo no se registra a $P$. bilimeki, ambas especies podrían coincidir en su distribución cuando se generen más muestras de otras partes del norte de Colombia. El margen posterior de la cabeza de las soldados de $P$. bilimeki varía alopátricamente desde levemente cóncavo a fuertemente excavado formando una V y dos lóbulos laterales anchos (Longino y Cox 2009), mientras que las soldados de $P$. urbana presentan una concavidad profunda y relativamente más ancha hacia el centro del margen posterior de la cabeza y dos lóbulos posterolaterales estrechos y pronunciados. Así mismo, la cabeza en P. bilimeki presenta carínulas gruesas notablemente separadas entre sí hacia la región dorsal anteromedial, y con un área fuertemente foveada donde reposan los escapos, mientras que en $P$. urbana la región dorsal anteromedia de la cabeza presenta carínulas delgadas muy apretadas, extendiéndose apenas hasta la mitad de la frente. En P. bilimeki el dorso posterior de la cabeza con la superficie densamente foveada, con carínulas tenues que se extiende hacia el vértex, y opaca, contrastando con $P$. urbana donde es lisa y muy brillante. En vista lateral, las soldados de
P. bilimeki presentan el promesonoto relativamente más alto y convexo que el de esa misma casta en $P$. urbana. Las espinas propodeales en $P$. bilimeki son agudas, relativamente largas y dirigidas hacia arriba, mientras que en las soldados de $P$. urbana las espinas son muy cortas, casi tan altas como anchas. Por último, las soldados de $P$. bilimeki presentan abundantes pelos largos sobre la cabeza, mesosoma y gáster, mientras que las de $P$. urbana son cortos entre semierectos y recostados, poco abundantes, y sin pelos de cualquier tipo en el dorso del propodeo.

Las obreras son relativamente muy similares entre sí, pero discrepan en lo esculpido de la superficie del dorso de la cabeza. En P. bilimeki es densa y completamente foveada, mientras que en $P$. urbana combina áreas foveadas con rugoreticuladas. El vértice posterior en $P$. urbana es recto mientras que en $P$. bilimeki presenta una concavidad amplia y poco profunda en la mitad. El propodeo en $P$. bilimeki está muy por debajo del promesonoto, mientras que el de $P$. urbana está al mismo nivel. En ambos casos, el propodeo está armado, pero en $P$. urbana no hay espinas sino proyecciones triangulares tan altas como anchas, mientras que en $P$. bilimeki las espinas son relativamente largas y dirigidas hacia atrás. Los pelos en el mesosoma de $P$. bilimeki son aplastados, con cuatro en el perfil del promesonoto y uno en el perfil propodeal; $P$. urbana solo tiene cuatro pelos aplastados en el perfil del promesonoto, y sin pelos en el propodeo. Los pelos del peciolo, pospeciolo y gáster son relativamente similares entre las obreras de ambas especies, largos y cilíndricos, pero más gruesos en P. urbana.
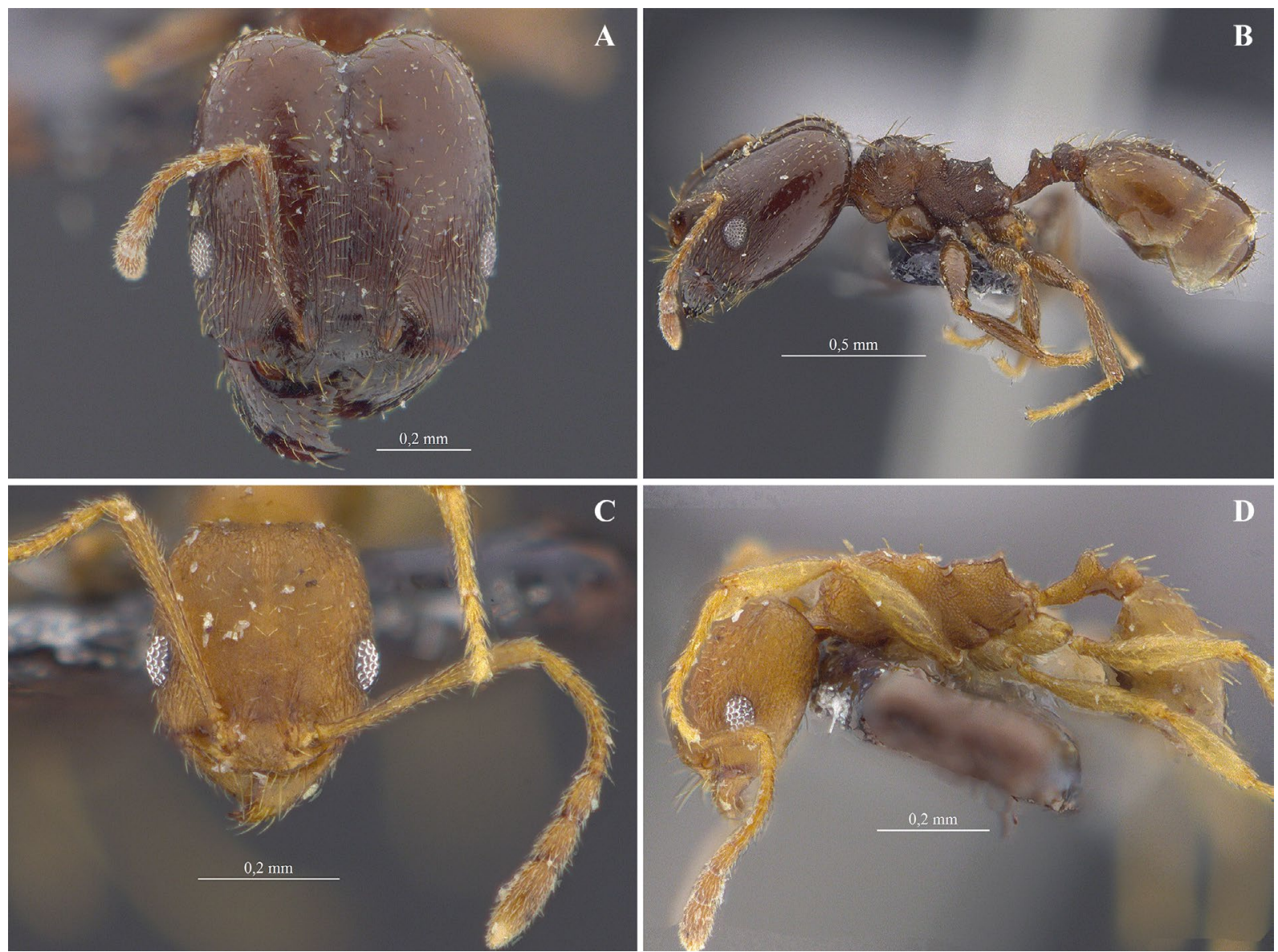

Figura 14. Hábito de Pheidole urbana sp. n. A. Cabeza en vista frontal de la soldado. B. Cuerpo en vista lateral de la soldado. C. Cuerpo en vista frontal de la obrera. D. Cuerpo en vista lateral de la obrera. Fotografías de soldado (CBUMAG:ENT11175) y obrera (CBUMAG:ENT11180) por R. J. Guerrero. 
Biología. Esta especie anida en suelos arcillosos, siempre cerca árboles o troncos caídos, aunque también se han encontrado colonias al interior de casas en áreas urbanas (RJG obs. pers.). Las soldados y obreras forrajean comúnmente en el suelo y llegan fácilmente a los cebos.

Etimología. El nombre urbana es una forma latinizada del vocablo urbano, y es utilizada aquí de forma invariable para describir la preferencia de esta especie hacia ambientes abiertos y frecuentemente modificados como son las áreas de parques y zonas residenciales en Santa Marta (Colombia).

Material examinado. 6 soldados, 8 obreras. COLOMBIA. Magdalena, Santa Marta, Taganga, $11^{\circ} 16^{\prime} 4,91^{\prime \prime} \mathrm{N}$ $74^{\circ} 11^{\prime} 15,18^{\prime} \mathrm{O}, 50 \mathrm{~m}$, captura manual, 23-sep-2018. Camargo, J. [CBUMAG].

\section{Discusión}

Este es el primer estudio enfocado en la diversidad taxonómica del género Pheidole en Colombia. Para el bosque seco tropical de la región de Santa Marta se registran 13 especies, lo que equivale a aproximadamente el 9,5\% de las especies Pheidole conocidas para el territorio colombiano. Dentro de este ensamblaje de especies, se describe la nueva especie $P$. urbana y documentan dos nuevos registros para el país ( $P$. impressa y $P$. leptina). Integrando estos nuevos hallazgos a otros trabajos que incluyeron a la fauna de Pheidole (Zabala et al. 2006; Fernández 2011; Guerrero et al. 2018), la riqueza de este género de hormigas en Colombia se incrementa a 111 especies formalmente descritas. Estos resultados sugieren que la diversidad del género Pheidole en Colombia es relativamente alta y cercana a la de Costa Rica (157 especies; Longino (2019)) y Brasil (150 especies; Ferreira 2016), donde la fauna de hormigas ha sido relativamente mejor estudiada (Guerrero et al. 2018).

La diversidad de hormigas Pheidole encontrada en las formaciones vegetales secas del área de Santa Marta es similar a registrada por Chacón de Ulloa et al. (2012) para diferentes fragmentos de bosque seco abarcando los departamentos de Risaralda, Cauca y Valle del Cauca (13 morfoespecies). Así mismo la riqueza del género para los fragmentos en Santa Marta es mayor si se compara con los estudios realizados por Dominguez-Haydar y Armbrecht (2011) y Fontalvo-Rodríguez y Solís-Medina (2009), donde se registraron 11 y nueve morfoespecies, respectivamente, en parches de bosque seco en el departamento de La Guajira.

Los valores de riqueza y composición de especies del género variaron entre los sitios de muestreo (Tabla 2), posiblemente por la complejidad ecológica de los sitios (Economo et al. 2015), la cual puede estar moldeada por las variaciones microclimáticas o la composición y cobertura vegetal de cada uno de los sitios estudiados. Los sitios de muestreo que registraron mayor riqueza de especies fueron Puerto Mosquito y la Reserva Biológica Caoba, siendo las estaciones con mayor cobertura vegetal (bosque primario, secundario ribereño) incluyendo familias de plantas predominantes tales como Anacardiaceae (R.Br.) Lindl., Capparaceae Juss., Malvaceae Juss., y Fabaceae Lindl. (Martínez et al. 2009); dichas características proveen una amplia diversidad de recursos alimenticios y microhábitats que se traducen en un mayor número de recursos ecológicos aprovechables por las especies de Pheidole. Por el contrario, la formación vegetal en Taganga y la parcela del bosque seco de la UniMagdalena registraron menor número de especies, en donde factores como la homogeneidad del hábitat, la baja calidad del suelo en ambientes extremadamente secos, el déficit significativo de precipitaciones, la poca área muestreable y la constante presión antropogénica podrían ser limitantes para el establecimiento de poblaciones de otras especies de Pheidole registradas en ambientes boscosos relativamente cercanos.

Las hormigas del género Pheidole se encontraron en una amplia variedad de hábitats (áreas conservadas/degradadas, bordes e interiores de los bosques, cerca al río y en zonas urbanas), siendo organismos bastante representativos en los sitios estudiados y de gran importancia ecológica involucrándose en diferentes niveles tróficos y desempeñando diversas funciones tales como la dispersión y remoción de semillas, depredación de animales vivos o muertos y sirviendo como alimento para otros organismos (Eguchi 2008). Los sitios de anidación más comunes de Pheidole incluyen suelo, el interior de las ramas secas y la hojarasca (Wilson 2003). Aunque en este estudio se recolectaron algunas especies dentro de troncos caídos en descomposición, la mayoría de las especies fueron recolectadas directamente de nidos en el suelo; Wilson (2003) afirma que la prevalencia de las especies Pheidole está fundamentada en el alto número de colonias y obreras que presenta el grupo, especialmente en el suelo, lo que explica su amplia distribución geográfica.

Por último, los estudios enfocados a la taxonomía y diversidad del género Pheidole carecen de un método adecuado de identificación: 1. las claves propuestas por Wilson (2003) están diseñadas solo para soldados, cuyo uso se dificulta porque 2. las soldados son poco recolectados en métodos de captura pasivos (sacos winkler o trampas de caída), derivando en 3. las obreras, abundantemente recolectadas, son difíciles de asociar con soldados esporádicos. Para resolver estos problemas circunstanciales, se sugiere la implementación del método de captura a través de atrayentes (cebos con proteína animal y carbohidratos), los cuales permiten el rastreo hacia los nidos y por ende la recolección y análisis de las castas; además, este tipo de estudios siempre deben considerar el análisis de la variación morfológica de las poblaciones de las especies del género Pheidole, porque con ello se garantiza la correcta identificación y delimitación de las especies. La aplicación de estos aspectos metodológicos, además del uso de colecciones de referencia, claves taxonómicas interactivas y bibliotecas de imágenes, permitirán decrecer la incertidumbre taxonómica que en la mayoría de los casos se presenta con las especies del género Pheidole (Vicente et al. 2018).

\section{Agradecimientos}

A Paula Sepúlveda, Sigmer Quiroga y Mayron Escárraga por los aportes sugeridos al manuscrito. Emira García generó las fotografías de $P$. impressa. Las fotografías fueron generadas en el laboratorio de Entomología de la Universidad del Magdalena a cargo de Paula Sepúlveda. Mayron E. Escárraga ayudó en la elaboración del mapa del área de estudio. A los tres árbitros anónimos por las sugerencias y comentarios que mejoraron la calidad científica de esta contribución. También a "Jack" Longino de la Universidad de Utah (Estados Unidos de Norte América) por compartir una versión actualizada de la Lucid Key del Pheidole Working Group. Esta es la contribución $\mathrm{N}^{\circ} 02$ del proyecto de investigación "Taxonomía y distribución de las hormigas Pheidole (Formicidae: Myrmicinae) de Colombia" financiado por el fondo para la ciencia de la Universidad del Magdalena - Fonciencias a través del 
Acuerdo 006 de 2016. Todo el material derivado de esta investigación se encuentra depositado en las Colecciones Biológicas del Centro de Colecciones Científicas de la Universidad del Magdalena, siguiendo el consecutivo de publicaciones número 14.

\section{Literatura citada}

ACHURY, R.; CHACÓN DE ULlOA, P.; ARCILA, A. 2012. Effects of the heterogeneity of the landscape and the abundance of Wasmannia auropunctata on ground ant assemblages in a Colombian tropical dry forest. Psyche: A Journal of Entomology 2012: 960475. https://doi.org/10.1155/2012/960475

ANTWEB. 2019. AntWeb. California Academy of Science. Disponible en: http://www.antweb.org. [Fecha revisión: 21 febrero 2019].

BOLTON, B. 2020. An online catalog of the ants of the world. Disponible en: https://www.antcat.org/. [Fecha revisión: 12 marzo 2020].

CHACÓN DE ULLOA, P.; OSORIO-GARCÍA, A. M.; ACHURY, R.; R. BERMÚDEZ-RIVAS, C. 2012. Hormigas (Hymenoptera: Formicidae) del bosque seco tropical (Bs-T) de la cuenca alta del río Cauca, Colombia. Biota Colombiana 13 (2): 29. http:// revistas.humboldt.org.co/index.php/biota/article/view/266/264

DELSINNE, T.; SERNA, F. J.; LEPONCE, M; BOUDINOT, B. E. 2019. Glosario de morfología. pp. 387-457. En: Fernández, F.; Guerrero, R. J.; Delsinne, T. (Eds.). Hormigas de Colombia. Editorial UN, Bogotá, D. C., Colombia. 1197 p.

DOMINGUEZ-HAYDAR, Y.; ARMBRECHT, I. 2011. Response of ants and their seed removal in rehabilitation areas and forests at El Cerrejon coal mine in Colombia. Restoration Ecology 19 (201): 178-184. https://doi.org/10.1111/j.1526-100X.2010.00735.x

ECONOMO, E. P.; KLIMOV, P.; SARNAT, E. M.; GUÉNARD, B.; WEISER, M. D.; LECROQ, B.; KNOWLES, L. L. 2015. Global phylogenetic structure of the hyperdiverse ant genus Pheidole reveals the repeated evolution of macroecological patterns. Proceedings of the Royal Society B 282: 20141416. https://doi. org/10.1098/rspb.2014.1416

EGUCHI, K. 2008. A revision of Northern Vietnamese species of the ant genus Pheidole (Insecta: Hymenoptera: Formicidae: Myrmicinae). Zootaxa 1902: 1-118. http://dx.doi.org/10.11646/ zootaxa.1902.1.1

FERNÁNDEZ, F. 2003. Introducción a las hormigas de la región Neotropical. Instituto de Investigación de Recursos Biológicos Alexander von Humboldt, Bogotá, Colombia. XXVI. 398 p.

FERNÁNDEZ, F. 2011. Pheidole iceni n. sp. (Hymenoptera: Formicidae), a new ant for an old institution. Caldasia 33 (2): 665-670. https://revistas.unal.edu.co/index.php/cal/article/view/36418

FERNÁNDEZ, F.; SERNA F. J. 2019. Subfamilia Myrmicinae. pp. 791-888. En Fernández, F.; Guerrero, R. J.; Delsinne, T. (Eds.). Hormigas de Colombia. Editorial UN, Bogotá, D.C., Colombia. 1198 p.

FERREIRA, A. C. 2016. O gênero Pheidole (Hymenoptera: Formicidae: Myrmicinae) no paraná: levantamento e delimitação de espécies. Universidade Federal do Paraná, Brasil. 389 p. http:// hdl.handle.net/1884/48373

FISCHER, G.; HITA GARCIA, F.; PETERS, M. K. 2012. Taxonomy of the ant genus Pheidole Westwood (Hymenoptera: Formicidae) in the Afrotropical zoogeographic region: definition of species groups and systematic revision of the Pheidole pulchella group. Zootaxa 3232: 1-43. https://dx.doi.org/10.11646/zootaxa.3232.1.1

FONTALVO-RODRÍGUEZ, L.; SOLÍS-MEDINA, C. 2009. Ensamble de hormigas (Hymenoptera: Formicidae) en fragmentos de bosque seco en el complejo carbonífero el Cerrejón (La Guajira, Colombia). Intropica 27: 5-15. http://revistas.unimagdalena. edu.co/index.php/intropica/article/view/134/117

GIRALDO, Y. M.; PATEL, E.; GRONENBERG, W.; TRANIELLO, J. F. A. 2013. Division of labor and structural plasticity in an extrinsic serotonergic mushroom body neuron in the ant Pheidole dentata. Neuroscience Letters 534: 107-111. http:// doi.org/10.1016/j.neulet.2012.11.057

GUERRERO, R. J.; FERNÁNDEZ, F.; ESCÁRRAGA, M. E.; PÉREZ-PEDRAZA, L. F.; SERNA, F.; MAcKAY, W. P.; SANDOVAL, V.; VERGARA, V.; SUÁREZ, D.; GARCÍA, I.; SÁNCHEZ, A.; MENESES, A. D.; TOCORA, M. C.; SOSA-CALVO, J. 2018. New records of myrmicine ants (Hymenoptera: Formicidae) for Colombia. Revista Colombiana de Entomología 44 (2): 238-259. https://doi.org/10.25100/socolen.v44i2.7115

GUERRERO, R. J.; DELSINNE, T; DEKONINC, W. 2019. Métodos de recolección y curaduría. pp. 319-370. En: Fernández, F.; Guerrero, R. J.; Delsinne, T. (Eds.). Hormigas de Colombia. Editorial UN, Bogotá, D. C., Colombia. 1198 p.

HARRIS, R. A. 1979. A glossary of surface sculpturing. California Department of Food and Agriculture, Bureau of Entomology 28: $1-31$.

IGLESIAS CÓRDOBA, L.; JOHNSON SALCEDO, V. L.; RITSEL FESKE, E. 2008. Estrategias de comercialización turística internacional de las playas del rodadero, Taganga y Bahía Concha. Tesis de maestría. Universidad del Norte. Barranquilla, Colombia. 98 p. http://manglar.uninorte.edu.co/handle/10584/176\#pa$\mathrm{ge}=2$

LILLICO-OUACHOUR, A.; METSCHER, B.; KAJI, T.; ABOUHEIF, E. 2018. Internal head morphology of minor workers and soldiers in the hyperdiverse ant genus Pheidole. Canadian Journal of Zoology 96 (5): 383-392. https://dx.doi.org/10.1139/ cjz-2017-0209

LONGINO, J. T. 2009a. Pheidole Working Group. Disponible en: https://ants.biology.utah.edu/pheidoleworkinggroup/index.htm. [Fecha revisión: 21 febrero 2019].

LONGINO, J. T. 2009b. Additions to the taxonomy of New World Pheidole (Hymenoptera: Formicidae). Zootaxa 2181 (1): 1-90. https://dx.doi.org/10.11646/zootaxa.2181.1.1

LONGINO, J. T. 2019. Pheidole (Hymenoptera, Formicidae) of Middle American wet forest. Zootaxa 4599 (1): 001-126. https:// dx.doi.org/10.11646/zootaxa.4599.1.1

LONGINO, J. T.; COX, D. J. 2009. Pheidole bilimeki reconsidered (Hymenoptera: Formicidae). Zootaxa 1985 (1): 34-42. https:// dx.doi.org/10.11646/zootaxa.1985.1.3

MARTÍNEZ, N. J.; GARCÍA, H.; PULIDO, L. A.; OSPINO, D.; NARVÁEZ, J. C. 2009. Escarabajos coprófagos (Coleoptera: Scarabaeinae) de la Vertiente Noroccidental, Sierra Nevada de Santa Marta, Colombia. Neotropical Entomology 38 (6): 708715. https://doi.org/10.1590/S1519-566X2009000600002

MERTL, A. L.; SORENSON, M. D.; TRANIELLO, J. F. A. 2010. Community-level interactions and functional ecology of major workers in the hyperdiverse ground-foraging Pheidole (Hymenoptera, Formicidae) of Amazonian Ecuador. Insectes Sociaux 57: 441-452. https://doi.org/10.1007/s00040-010-0102-5

MOREAU, C. S. 2008. Unraveling the evolutionary history of the hyperdiverse ant genus Pheidole (Hymenoptera: Formicidae). Molecular Phylogenetics and Evolution 48 (1): 224-239. https:// doi.org/10.1016/j.ympev.2008.02.020

NATURAL EARTH. 2019. Natural Earth 2.0. Free vector and raster map data. Disponible en: https://www.naturalearthdata.com. [Fecha revisión: 21 febrero 2019].

NORIEGA, A. J. A.; BARRANCO, W.; HERNÁNDEZ, J.; HERNÁNDEZ, E.; CASTILLO, S.; MONROY, D.; GARCÍA, H. 2016. Estructura estacional del ensamblaje de escarabajos coprófagos (Coleoptera: Scarabaeinae) en una parcela permanente de bosque seco tropical. Revista de la Academia Colombiana de Ciencias Exactas, Físicas y Naturales, 40 (154): 75-83. https:// doi.org/10.18257/raccefyn.255

PEETERS, C. 2019. Castas. Homología y analogía en la forma y función. pp. 917-1053. En: Fernández, F.; Guerrero, R. J.; Delsinne, T. (Eds.). Hormigas de Colombia. Editorial UN, Bogotá, D. C., Colombia. 1198 p. 
SARNAT, E. M.; MOREAU, C. S. 2011. Biogeography and morphological evolution in a Pacific island ant radiation. Molecular Ecology 20 (1): 114-130. https://doi.org/10.1111/ j.1365-294X.2010.04916.X

SERNA, F. J.; SUÁREZ, D; PÉREZ, A. L. 2019. Género Pheidole. pp. 917-1053. En: Fernández, F.; Guerrero, R. J.; Delsinne, T. (Eds.). Hormigas de Colombia. Editorial UN, Bogotá, D. C., Colombia. 1198 p.

STREWE, R.; VILLA-DE LEÓN, C.; ALZATE, J.; BELTRÁN, J.; MOYA, J.; NAVARRO, C.; UTRÍA, G. 2009. Las aves del campus de la Universidad del Magdalena, Santa Marta, Colombia. Revista Intropica 4: 79-91. https://revistas.unimagdalena.edu.co/ index.php/intropica/article/view/141/123

TAMARIS-TURIZO, C.; RODRÍGUEZ-BARRIOS, J.; OSPINATORRES, R. 2013. Deriva de macroinvertebrados acuáticos a lo largo del río Gaira, vertiente noroccidental de la Sierra Nevada de Santa Marta, Colombia. Caldasia 35 (1): 149-163. https://revistas.unal.edu.co/index.php/cal/article/view/39103

TEAM QGIS DEVELOPMENT. 2016. QGIS geographic information system. Open Source Geospatial Foundation Project.

VICENTE, R. E.; FERREIRA, A. C.; SANTOS, R. C. L.; PRADO, L. P. 2018. Ants (Hymenoptera: Formicidae) from an Amazonian fragmented landscape, Juara, Mato Grosso, Brazil, with new records of ant species. Papéis Avulsos de Zoologia 58: e20185840. https://doi.org/10.11606/1807-0205/2018.58.40

WILSON, E. 2003. Pheidole in the New World: a dominant, hyperdiverse ant genus. Harvard University Press, Cambridge, Massachusetts, EE. UU. 794 p.
ZABALA, E. G.; VÉLEZ, H. M.; GÓNGORA, B. C. 2006. Nuevos registros de especies de hormigas (Hymenoptera: Formicidae) para Colombia. Revista Colombiana de Entomología 32 (2): 227 229. https://doi.org/10.25100/socolen.v32i2.9395

\section{Origen y financiación}

Los resultados aqui presentados derivaron del trabajo de investigación del primer autor, el cual lo desarrollo como requisito parcial para optar al título de biólogo otorgado por la Universidad del Magdalena. Este trabajo hizo parte del proyecto de investigación Taxonomía y distribución de las hormigas Pheidole (Formicidae: Myrmicinae) en Colombia, el cual fue financiado por el fondo para la ciencia de la Universidad del Magdalena - Fonciencias, a través del Acuerdo 006 de 2016

\section{Contribución de los autores}

José J. Camargo-Vanegas desarrolló toda la fase de muestreo, separación de las muestras, montaje y preparación de la colección de referencia e identificación taxonómica de las hormigas Pheidole, así como la descripción de las especies y redacción del manuscrito.

Roberto J. Guerrero participó en la definición de la metodología de muestreo, identificación y descripción de las diferentes especies de Pheidole, incluyendo la nueva especie para la ciencia. Además, contribuyó en la redacción y revisión de las ideas expuestas en el manuscrito, y generó las fotografías multifoco que ilustran a las especies registradas en esta contribución. 